\title{
Um modelo de fluxos e localização de terminais intermodais para escoamento da soja brasileira destinada à exportação
}

\section{A model for flow allocation and location of intermodal terminals for the Brazilian soybean exports}

\author{
Mônica do Amaral ${ }^{1}$ \\ Marina Soares Almeida ${ }^{1}$ \\ Reinaldo Morabito ${ }^{1}$
}

\begin{abstract}
Resumo: A consideração de rotas intermodais pode ser vantajosa em diversas situações, como nos casos de escoamento de produtos agrícolas para exportação. Entretanto, a possibilidade de redução dos custos logísticos está condicionada à existência de instalações que permitam o transbordo de carga e a integração entre os modais disponíveis. Nesse contexto, propõe-se um modelo de fluxos e localização de terminais intermodais, com o objetivo de apoiar decisões de investimento em infraestrutura e de roteirização na rede. O modelo possui forte relação com problemas de $p$-medianas, sabidamente NP-difíceis. São considerados múltiplos níveis, em que cada nível corresponde ao fluxo entre dois terminais, e uma estrutura esparsa para representação da rede. Testes realizados com uma rede para exportação de soja baseada em dados secundários foram utilizados para verificar a coerência e ilustrar o potencial de análise do modelo, enquanto instâncias geradas aleatoriamente serviram para avaliar seu desempenho computacional utilizando-se dois softwares de otimização.
\end{abstract}

Palavras-chave: Localização de instalações. Fluxos em rede. Transporte intermodal. Logística. Exportação de soja.

\begin{abstract}
The use of intermodal routes may be advantageous in several situations such as to export agricultural products. However, the possibility of reducing logistics costs depends on the existence of intermodal facilities for the transshipment and the integration between the available modes. In this context, we propose a model for flow allocation and location of intermodal terminals to support investment decisions in network infrastructure and routing. The model is closely related to the NP-hard p-median problem. Multiple levels were used to represent the flows between two terminals, and a sparse structure was used for the network matrix representation. Tests using a soybean network for exports based on secondary data were performed to verify the model consistency and to illustrate the potential of analysis of the model, while randomly generated instances were used to evaluate its computational performance using two kinds of optimization software.
\end{abstract}

Keywords: Facility location. Network flows. Intermodal transport. Logistics. Soybean exports.

\section{Introdução}

Em muitas situações, os pontos de produção e consumo de uma cadeia de suprimentos se encontram geograficamente muito dispersos, exigindo que os produtos sejam transportados por longas distâncias. Nesses casos, controlar os custos de transporte pode ser fundamental para a lucratividade do negócio (KERBACHE; SMITH, 2004). A soja, por exemplo, é um dos principais produtos agrícolas produzidos e exportados pelo Brasil, correspondendo a aproximadamente $44 \%$ do volume total de grãos (ASSOCIAÇÃO..., 2009). A partir do Centro-Oeste, que é a região de maior produção, a soja percorre grandes distâncias para chegar aos principais portos no Sudeste e Sul. Como consequência, os custos de transporte representam cerca de $25 \%$ do total e influenciam diretamente o preço do produto no mercado internacional.

Nesse caso, a intermodalidade surge como uma alternativa para tornar o escoamento da soja mais econômico. No entanto, deve-se destacar o fato de que o funcionamento eficiente do transporte de cargas por mais de um modal depende não só da disponibilidade dos modais em si, mas também da existência de estruturas de apoio, como terminais intermodais. Caso contrário, o transporte intermodal pode se tornar menos efetivo em custos, consumir

\footnotetext{
${ }^{1}$ Universidade Federal de São Carlos - UFSCar, Rod. Washington Luís, Km 235, CEP 13565-905, São Carlos, SP, Brasil, e-mail: monica@dep.ufscar.br; marinasoares@dep.ufscar.br; morabito@ufscar.br
}

Recebido em 20/2/2010 — Aceito em 8/8/2011 
maior tempo e ser menos confiável que o transporte rodoviário (KONINGS, 1996).

$\mathrm{O}$ termo transporte intermodal pode ser definido como o movimento de cargas entre uma origem e um destino por pelo menos dois modais diferentes (CHANG, 2008). Para Macharis e Bontekoning (2004), as distâncias percorridas por rodovias devem ser as menores possíveis e, para cargas conteinerizadas, não podem ocorrer trocas de contêiner ao longo da rota. No Brasil, de acordo com a Lei 9.611/98, o termo transporte intermodal não tem significado legal e a denominação correta é transporte multimodal, devendo ser realizado sob a responsabilidade de um operador de transporte multimodal e regido por um contrato único. Eventualmente, além do transporte, podem ser realizados outros serviços, tais como coleta, armazenagem, consolidação/desagregação e entrega da carga (AGÊNCIA..., 2010). Apesar disso, manter-se-á aqui a denominação mais usual dentro da comunidade científica internacional.

Embora a intermodalidade seja reconhecida como um meio bastante promissor para a redução dos custos logísticos (CHANG, 2008), Bontekoning, Macharis e Trip (2004) acreditam que a área de estudo seja relativamente recente, podendo-se observar um crescimento acentuado no número de publicações nas últimas três décadas. Uma das motivações para esse aumento é o crescente investimento de órgãos governamentais nessas pesquisas. Nesse aspecto, merecem destaque os incentivos da Conferência Européia dos Ministros dos Transportes e da Associação Americana de Ferrovias. No Brasil, pode-se citar principalmente o trabalho realizado pelo Grupo Executivo de Integração da Política de Transportes (GRUPO..., 2001). E, mais recentemente, o Projeto ALOGTRANS, relacionado ao estudo dos corredores de escoamento de produtos agroindustriais, financiado pela FINEP (Financiadora de Estudos e Projetos do Ministério da Ciência e Tecnologia), no qual o presente trabalho está inserido.

Tem-se por objetivo, neste trabalho, apoiar decisões de investimento em infraestrutura, por meio da aplicação de um modelo de fluxos para localização de terminais intermodais aos principais corredores usados para a exportação da soja brasileira, organizando os fluxos da forma mais econômica possível. São consideradas restrições de conservação de fluxo, além de limitações no número e na capacidade dos terminais intermodais a serem instalados na rede.

Este trabalho está organizado da seguinte maneira: na seção 2, apresenta-se uma breve revisão bibliográfica voltada aos trabalhos quantitativos em transporte intermodal, destacando-se alguns modelos relacionados à localização de terminais intermodais e ao desenvolvimento de estudos práticos aplicados à agroindustria brasileira. A seguir, na seção 3 , o problema de localização de terminais intermodais em redes de exportação é apresentado e formulado matematicamente. Discutem-se também as premissas utilizadas no processo de adaptação do modelo proposto por Arnold, Peeters e Thomas (2004), a estrutura esparsa utilizada para a representação da rede e algumas extensões possíveis. Na seção 4, são apresentados os resultados computacionais. Primeiramente, instâncias baseadas em dados secundários são utilizadas para verificar a coerência e ilustrar o potencial de análise do modelo. Em seguida, discutem-se alguns aspectos referentes ao comportamento e ao desempenho computacional do modelo em testes realizados utilizando-se dois softwares de otimização e dados gerados aleatoriamente. Encerra-se o trabalho, na seção 5, com algumas considerações a respeito da aplicabilidade do modelo e algumas perspectivas para trabalhos futuros.

\section{Revisão de literatura}

Macharis e Bontekoning (2004) formalizaram algumas classes de problemas quantitativos, definidos de acordo com o ponto de vista do tomador de decisões: $(i)$ as operações com caminhões, voltadas às atividades de coleta e entrega de carga, entre os terminais intermodais e os produtores ou clientes finais; (ii) as operações intermodais, cujo foco é otimizar os fluxos internos aos terminais intermodais; (iii) as operações de infraestrutura de rede, que têm por objetivo planejar mudanças físicas e prever seus impactos nos fluxos do sistema; (iv) as operações de roteirização, que buscam a minimização dos custos de transporte, considerando somente a estrutura física já existente. Em cada classe, o horizonte de planejamento foi utilizado para definir subclasses desses problemas.

A classe de problemas que envolve decisões de infraestrutura da rede intermodal concentra grande número de trabalhos, voltados principalmente para o projeto da rede e o estabelecimento de políticas de atribuição de fluxo. Dentre os principais modelos utilizados estão os de projeto de rede (network design), localização de instalações (facility location), sistemas eixo-raio (hub-and-spoke) e equilíbrio espacial de preços (spatial price equilibrium). De acordo com Arnold et al. (2001), esses trabalhos contemplam poucas aplicações práticas, embora estejam relacionados a modelos clássicos de otimização. Jaržemskienè (2007) observa que, apesar da facilidade de formulação, esses problemas são difíceis de resolver, devido ao aumento da complexidade computacional refletida pela explosão do número de variáveis binárias e de restrições que ocorre com o crescimento da rede considerada.

Problemas de localização de terminais intermodais se encontram nessa classe e são considerados problemas referentes a horizontes de longo prazo. Dentre os 
artigos revisados, merecem destaque os de Arnold et al. (2001) e Arnold, Peeters e Thomas (2004). No primeiro trabalho, foram discutidas seis formulações para o problema de localização de terminais em uma rede rodo-ferroviária. Posteriormente, uma formulação de menor complexidade computacional foi apresentada, juntamente com uma heurística, possibilitando o estudo de cenários reais na Península Ibérica. Mais recentemente, tem-se, por exemplo, os trabalhos de Racunica e Winter (2005), que propuseram um modelo para localização de terminais utilizando uma rede hub-and-spoke com custos côncavos não lineares, e Limbourg e Jourquim (2009) que propuseram um modelo de $p$-medianas para o mesmo fim e apresentaram um estudo de caso realizado na Europa.

O Brasil, apesar da sua grande extensão territorial, ainda utiliza pouco o transporte intermodal, quando comparado a outras áreas de comércio intenso, como a Região dos Grandes Lagos e a União Européia. No entanto, muitas pesquisas vêm sendo desenvolvidas no sentido de avaliar a estrutura de transporte disponível e apontar alternativas que levem ao seu melhor aproveitamento e expansão, especialmente no que se refere à redução de custos de escoamento de produtos agroindustriais para exportação. Grande parte dos trabalhos se concentra nas duas últimas classes, isto é, estão preocupados com o projeto e a roteirização da rede. Mas também é possível encontrar trabalhos voltados às operações com caminhões, como o de Oliveira (2005a), que utilizou modelos de roteirização de veículos e de localização de instalações para auxiliar decisões de coleta da produção de soja de Campo Mourão-PR.

Os trabalhos que têm por objetivo otimizar fluxos estão baseados principalmente em modelos de programação linear ou simulação e utilizam cenários para contrastar políticas de transporte atuais com possíveis situações futuras. Em otimização, destacam-se Ojima (2007), que comparou opções de frete rodoviário com rotas intermodais para exportar a soja do Mato Grosso, e Branco (2007), que avaliou cenários de demanda captável pela Estrada de Ferro Norte-Sul. Outros trabalhos interessantes, embora não explorem a intermodalidade, são os de Fernandes e Cezar (2005), voltados ao transporte de arroz na região de Sinop-MT, e os de Junqueira e Morabito (2006, 2008), em que um modelo para planejamento da produção, estocagem e logística de sementes de milho foi aplicado, usando dados realistas e de uma empresa do setor. Em simulação, Dalto (2003) propôs um sistema para determinar estratégias de comercialização de uma safra de soja e Coeli (2004) desenvolveu um estudo sobre as potencialidades de uso da Ferronorte como rota de exportação da soja do Centro-Oeste.

Dentre os trabalhos voltados à infraestrutura da rede, é possível encontrar modelos de equilíbrio espacial, transporte e armazenagem e localização de terminais. No primeiro grupo, destacam-se Ojima e Yamakami (2006) e Bulhões e Caixeta Filho (2000), que analisaram os fluxos da soja em diferentes contextos. Em relação ao uso de modelos de localização, tem-se trabalhos que exploram o transporte intermodal e a localização de armazéns, como Oliveira (2005b), Ferrari (2006) e Xavier (2008), que consideraram a exportação de açúcar em São Paulo, de soja pelo Mato Grosso e de álcool combustível no Brasil, respectivamente. No último grupo, Dubke (2006) propôs um modelo para localização de terminais especializados para a exportação de soja e derivados, cujo objetivo é determinar os serviços e as capacidades a serem instaladas em terminais nos principais portos brasileiros. Essas decisões dependem da lucratividade da soja em grão, do farelo ou do óleo, e dos custos fixos de investimento em armazéns, esmagadoras e refinarias, além dos custos variáveis de transporte na rede.

Embora algumas contribuições importantes já tenham sido dadas, ainda é possível apontar diversas oportunidades de pesquisas futuras envolvendo a questão da intermodalidade de transporte. Dentre elas, a possibilidade de desenvolver e aplicar modelos de fluxos e localização de terminais intermodais com múltiplos níveis em redes para escoamento de produtos agroindustriais, como a soja, largamente exportada pelo Brasil.

\section{O problema de fluxos e localização de terminais intermodais em redes de exportação}

O problema a ser analisado consiste em planejar a instalação de terminais intermodais em uma rede de transporte, permitindo o escoamento de produtos, como a soja em grão nesse caso específico, a partir dos pontos de oferta até os pontos de demanda, a um custo mínimo. Os pontos de oferta são as regiões produtoras de soja. Os pontos de demanda são os mercados consumidores internacionais. A rede também possui pontos intermediários, nos quais podem ser instalados terminais intermodais. Tanto as malhas viárias dos modais quanto os terminais intermodais são considerados como arcos nesta rede, enquanto os pontos de oferta, demanda e pontos intermediários se localizam nos vértices de um grafo orientado.

Dado o contexto acima, as variáveis de decisão correspondem a onde instalar os terminais intermodais e aos fluxos de soja nos arcos da rede. O problema está sujeito a restrições de conservação de fluxos, do número total de terminais intermodais a serem instalados e da capacidade de transbordo nos terminais intermodais. Esse pode ser visto como um problema de localização e alocação (location and allocation design problem), pois as decisões de atribuição de 
fluxos estão diretamente relacionadas às localizações selecionadas para as instalações na rede (GHIANI; LAPORTE; MUSMANNO, 2004). Trata-se, portanto, de um problema integrado de localização de instalações com fluxo de custo mínimo (AHUJA; MAGNANTI; ORLIN, 1993).

No que se refere à teoria de localização de instalações, o problema pode ser formulado como de $p$-medianas, $p$-centros ou considerar custos fixos de investimento (fixed charge location problem). Nos dois primeiros, o número de terminais a ser instalado assume um valor fixo $p$ e se deseja minimizar a soma das distâncias ou a distância máxima entre os clientes e as instalações, respectivamente. No último, depende do trade-off entre o investimento na rede e a redução dos custos de transporte (ARENALES et al., 2007).

Para a obtenção do fluxo de custo mínimo, a instalação de terminais intermodais em locais adequados permite o uso de modais mais baratos, como o ferroviário e o hidroviário para a transposição de longas distâncias, e o modal rodoviário apenas em pequenos trechos. Todos os pontos da rede, a rigor, podem ser considerados candidatos, mas pode ser útil simplificar o problema, considerando somente locais favorecidos pela sua posição relativa aos pontos de produção e consumo, evitando também a proximidade com terminais considerados antagônicos em função da concorrência por atração de carga (BALLIS; GOLIAS, 2004).

\subsection{Premissas adotadas}

Conforme mencionado, o modelo proposto consiste em uma extensão do trabalho de Arnold, Peeters e Thomas (2004), que foi aplicado a um sistema rodo-ferroviário de transporte de carga geral. A formulação foi adaptada para representar algumas das particularidades da exportação de soja, como mostrado na Tabela 1. As principais diferenças se encontram na descrição dos fluxos, que neste trabalho consideram apenas rotas de exportação entre regiões no interior do território brasileiro e outros países. Das regiões de plantio, a soja flui unidirecionalmente, utilizando os modais e os terminais intermodais disponíveis, incluindo-se os portos, de onde quantidades provenientes de diferentes regiões podem atender a qualquer região de demanda. Como os terminais intermodais são capacitados, podem surgir gargalos de fluxo, o que também difere da formulação original. No entanto, mantém-se a representação como um modelo de $p$-medianas, pela menor necessidade de dados a serem utilizados no modelo.

Também por simplicidade, os custos de transporte e transbordo são admitidos como sendo lineares, não considerando, portanto, economias de escala. A Figura 1 mostra a composição dos custos das rotas monomodais e intermodais e como a vantagem econômica da segunda forma é obtida em grandes distâncias. Para uma rota monomodal, apenas o custo de frete $c_{i j}$ é considerado, sendo proporcional à distância percorrida entre os pontos $i \mathrm{e} j$. Enquanto isso, uma rota intermodal considera os custos de frete dos modais utilizados em cada trecho $-c_{i k}, c_{k m}$ e $c_{m j}$, acrescidos das taxas de transbordo, que são dadas por $c_{k k}$ e $c_{m m}$. Além disso, considera-se que uma carga só pode entrar ou sair de uma ferrovia ou hidrovia a partir de um terminal intermodal. Essa premissa decorre da necessidade de uma estrutura que ofereça serviços de carga e descarga de trens ou barcaças. Assim, a partir de uma região de oferta, só pode haver fluxo rodoviário, a não ser que nesse ponto exista um terminal intermodal e o trecho rodoviário de coleta da soja nas fazendas possa ser desprezado.

\subsection{Representação da rede intermodal}

O sistema de transporte é representado por múltiplas redes, uma para cada modal considerado, como mostrado na Figura 2. Cada uma das redes de transporte pode ser representada por um grafo direcionado, $G_{m}=\left(V_{m}, A_{m}\right), m=\{1=$ modal rodoviário, $2=$ modal ferroviário, $3=$ modal hidroviário $\}$, em que $V_{m}$ representa o conjunto de vértices e $A_{m}$ o conjunto de arcos de cada modal, representados como setas horizontais cheias.

Um terminal intermodal é representado por um arco, utilizando-se as setas verticais tracejadas que conectam duas redes distintas. São permitidas diversas combinações de rotas, como nos exemplos: de Primavera do Leste-MT para o porto de Santos-SP, que passa pelo terminal rodo-ferroviário de Alto Taquari-MT, representada por $\mathbf{A 1} \rightarrow \mathbf{B 1} \rightarrow \mathbf{B 2} \rightarrow \mathbf{C 2}$; de Campo Novo do Parecis-MT para o porto de Itacoatiara-AM, passando pelo terminal rodo-hidroviário de Porto

Tabela 1. Comparação do modelo proposto com o trabalho utilizado como referência.

\begin{tabular}{ll}
\multicolumn{1}{c}{ Arnold, Peeters e Thomas (2004) } & \multicolumn{1}{c}{ Adaptações realizadas } \\
\hline Pacotes unitários & Decisões de fluxo \\
Origem-destino & Oferta-demanda \\
Fluxos bidirecionais & Fluxos unidirecionais \\
Sem restrições de capacidade & Terminais intermodais capacitados \\
Dois modais de transporte (rodoviário, ferroviário) & Três modais de transporte (rodoviário, ferroviário e hidroviário) \\
\hline
\end{tabular}




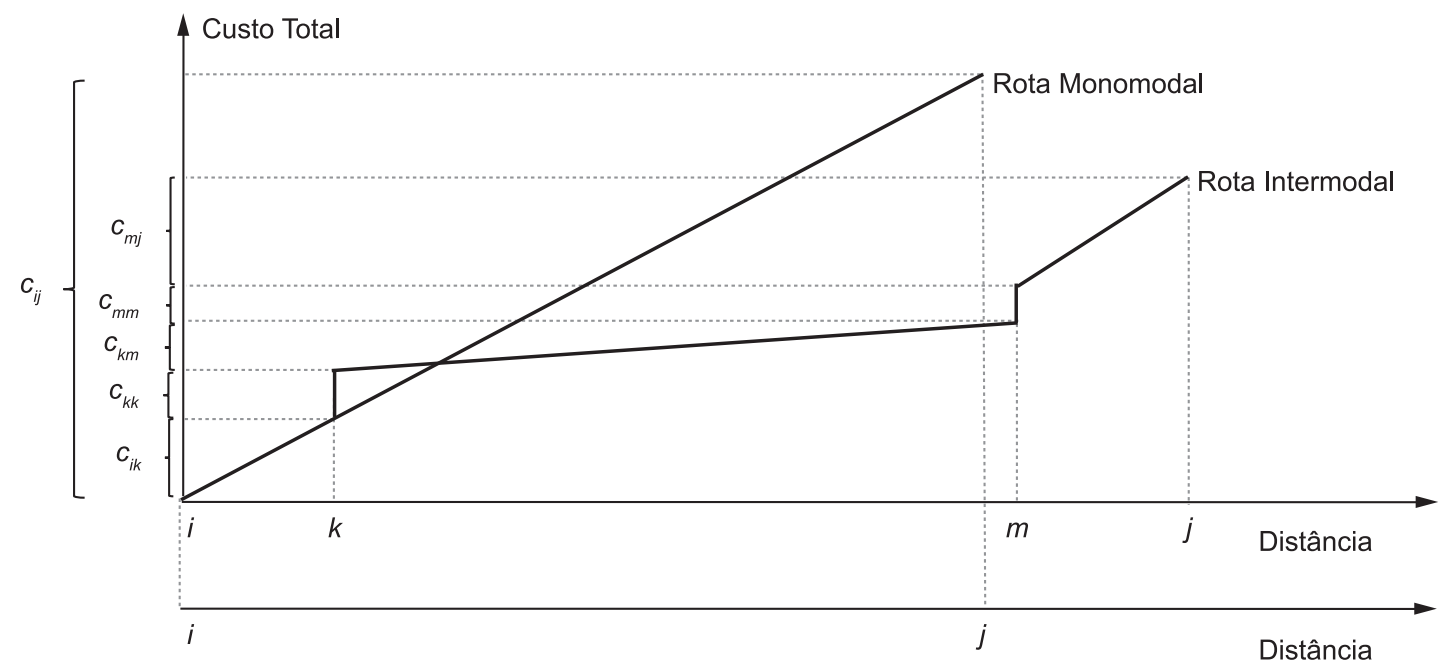

Figura 1. Composição de custos em rotas monomodais e intermodais.

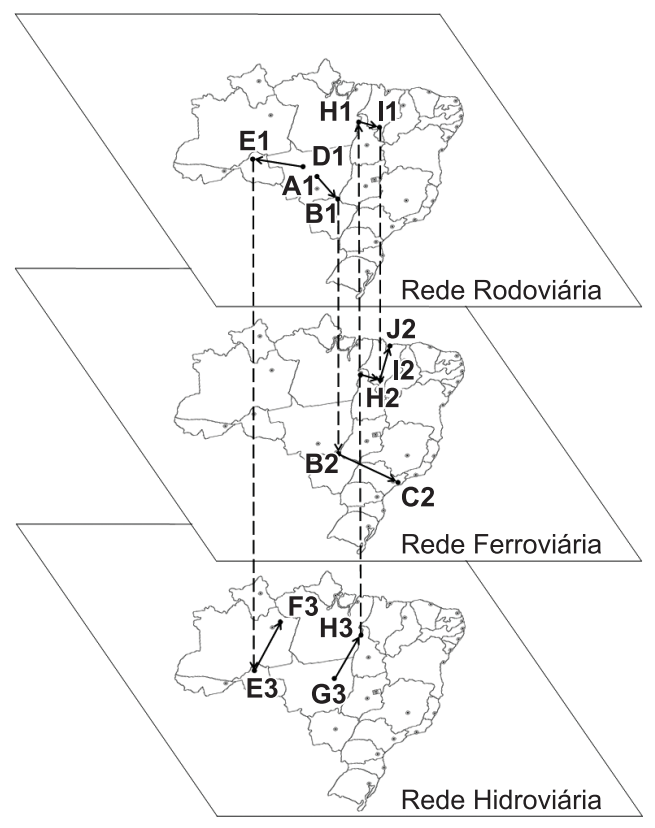

$\longrightarrow$ Transporte $\rightarrow-\rightarrow$ Transbordo

Figura 2. Representação em múltiplos níveis para uma rede de transporte intermodal.

Velho-RO, indicada por D1 $\rightarrow \mathbf{E} 1 \rightarrow \mathbf{E 3} \rightarrow \mathbf{F 3}$; de Nova Xavantina-MT para o porto de Itaqui-MA, que passa pelos terminais hidro-rodoviário de Xambioá-TO e rodo-ferroviário de Estreito-MA, mostrada em $\mathbf{~ G 3} \rightarrow \mathbf{H 3} \rightarrow \mathbf{H 1} \rightarrow \mathbf{I} 1 \rightarrow \mathbf{I} 2 \rightarrow \mathbf{J} 2$.

Existe ainda um conjunto $A^{\prime}$, com arcos que ligam os vértices em $O$, de oferta, e os vértices em $D$, de demanda, às redes modais. Dessa forma, tem-se a seguinte definição de conjuntos, formando um multigrafo direcionado, definido por $G=(V, A)$, em que o conjunto de vérices é dado por $V=O \cup D \cup V_{1} \cup V_{2} \cup V_{3}$ e o de $\operatorname{arcos}$ por $A=T \cup A^{\prime} \cup A_{1} \cup A_{2} \cup A_{3}$ :

- $O=$ Conjunto de vértices que representam os pontos de oferta;

- $D=$ Conjunto de vértices que representam os pontos de demanda;

- $V_{m}=$ Conjunto de vértices que representam os pontos de cada rede modal, $m=1,2,3$;

- $A_{m}=$ Conjunto de arcos de cada rede modal, $m=1,2,3$;

- $A^{\prime}=$ Conjunto de arcos que ligam os vértices de oferta e de demanda às rede modais;

- $T=$ Conjunto de arcos candidatos à instalação de terminais intermodais;

Os dois últimos podem, ainda, ser divididos nos seguintes subconjuntos disjuntos, sendo $A^{\prime}=A^{\prime}{ }_{0} \cup A^{\prime}{ }_{1 D} \cup A^{\prime}{ }_{2 D} \cup A^{\prime}{ }_{3 D} \mathrm{e}$ $T=T_{12} \cup T_{13} \cup T_{21} \cup T_{23} \cup T_{31} \cup T_{32}$, em que:

- $A^{\prime}{ }_{o}=$ Conjunto de arcos que ligam os vértices de oferta à rede rodoviária;

- $A^{\prime}{ }_{m D}=$ Conjunto de arcos que ligam os vértices das redes modais, $m=1,2,3$, aos vértices de demanda;

- $T_{m m}=$ Conjunto de terminais intermodais que ligam vértices dos modais $m$ e $m^{\prime}$, $\operatorname{com} m=1$, $2,3, m^{\prime}=1,2,3, m \neq m^{\prime}$.

A partir do exemplo da Figura 3a, em que se apresenta uma rede de exportação com $|O|=4,|D|=2$, $\left|V_{1}\right|=5,\left|V_{2}\right|=3$ e $\left|V_{3}\right|=4$, é possível perceber que a matriz de adjacências associada, mostrada em 3(b), apresenta uma estrutura esparsa. Dados os elementos dos conjuntos de vértices $O=\{\mathbf{0 1}, \mathbf{0 2}, \mathbf{0 3}, \mathbf{0 4}\}$, $D=\{\mathbf{d} 1, \mathbf{d} 2\}, V_{1}=\{\mathbf{r} 1, \mathbf{r} 2, \mathbf{r} 3, \mathbf{r} 4, \mathbf{r 5}\}, V_{2}=\{\mathbf{f 3}, \mathbf{f 4}$, f5 $\}$ e $V_{3}=\{\mathbf{h} \mathbf{1}, \mathbf{h} \mathbf{2}, \mathbf{h} \mathbf{4}, \mathbf{h} 5\}$ e de $\operatorname{arcos} A^{\prime}=\{(\mathbf{o 1}, \mathbf{r} \mathbf{2})$, $(01$, r4), (o1, r5), (02, r2), (02, r4), (03, r3), (03, r4), $($ o4, r4), (o4, r5), (r3, d1), (f3, d1), (f5, d1), (h1, d2), 
$(\mathbf{h} 4, \mathbf{d} 2),(\mathbf{h} 5, \mathbf{d} 2)\}, T=\{(\mathbf{r 3}, \mathbf{f 3}),(\mathbf{r} 1, \mathbf{h} 1),(\mathbf{r} 2, \mathbf{h} 2)$, $(\mathbf{r} 4, \mathbf{h} 4),(\mathbf{r 5}, \mathbf{h 5})\}, A_{1}=\{(\mathbf{r} \mathbf{2}, \mathbf{r 1}),(\mathbf{r 2}, \mathbf{r 3}),(\mathbf{r} 2, \mathbf{r 4})$, $(\mathbf{r} 2, \mathbf{r 5}),(\mathbf{r 3}, \mathbf{r 4}),(\mathbf{r 3}, \mathbf{r 5})\}, A_{2}=\{(\mathbf{f 3}, \mathbf{f 4}),(\mathbf{f 3}, \mathbf{f 5})\}$ e $A_{3}=\{(\mathbf{h} \mathbf{2}, \mathbf{h} \mathbf{1})\}$, podem-se identificar submatrizes de adjacência associadas aos conjuntos de arcos da rede. Por exemplo, a submatriz de dimensões $|O| \mathrm{x}\left|A_{1}\right|$, definida entre as linhas o1 e 04 e as colunas r1 e r5, representa os arcos de $A^{\prime}{ }_{O}$. Enquanto isso, os terminais intermodais do subconjunto $T_{12}$ estão relacionados à submatriz de adjacências entre as linhas $\mathbf{r} \mathbf{1}$ e r5 e as colunas $\mathbf{f 3}$ e $\mathbf{f 5}$, tendo dimensões $\left|A_{1}\right| \mathrm{x}\left|A_{2}\right|$; os arcos de transporte ferroviário são representados na submatriz entre as linhas e colunas $\mathbf{f 3}$ e f5, que tem dimensões $\left|A_{2}\right| \mathrm{x}\left|A_{2}\right|$; os arcos que ligam a rede hidroviária aos pontos de demanda estão representados na submatriz de dimensões $\left|A_{3}\right| \mathrm{x}|D|$, entre as linhas h1 e h5 e as colunas d1 e d2, e assim por diante.

\subsection{Formulação matemática}

Além das definições de conjuntos já apresentadas, a formulação do problema está baseada na seguinte definição de parâmetros:

- $a_{i}=$ Quantidade ofertada (t) pelo ponto $i,\{i \in O\}$;

- $b_{j}=$ Quantidade demandada (t) pelo ponto $j$, $\{j \in D\}$;

- $p=$ Número de terminais intermodais a serem instalados;

- $c_{i j}=$ Custo unitário $(\$)$ de transportar a carga pelo arco $(i, j),\{(i, j) \in A\}$

- $u_{i j}=$ Capacidade para o fluxo nos $\operatorname{arcos}(i, j) \mathrm{de}$ transbordo $(\mathrm{t}),\{(i, j) \in T\}$

Em relação aos custos, é importante observar que, para arcos pertencentes a $A_{l}$, os custos deverão refletir o frete rodoviário; para arcos pertencentes a $A_{2}$, o fretes ferroviários; e assim sucessivamente. Eventualmente, outros custos, como os de estoque em trânsito, podem ser incluídos. Entretanto, os arcos do conjunto $A$ ' podem representar custos em qualquer tipo de modal, caso estejam ligando os vértices da rede de transporte aos pontos de demanda; do contrário, representam custos de transporte rodoviário entre as ofertas e a rede rodoviária. Para arcos do conjunto $T$, finalmente, devem ser computados os custos de transbordo.

São definidas as seguintes variáveis de decisão:

$$
\begin{aligned}
& y_{i j}=\left\{\begin{array}{l}
1, \text { se um terminal intermodal é } \\
\text { instalado em }(i, j),\{(i, j) \in T\} \\
0, \text { caso contrário }
\end{array}\right. \\
& x_{i j}=\text { Fluxo no arco }(i, j),\{(i, j) \in A\}
\end{aligned}
$$

O modelo pode, então, ser formulado pelas Equações (1)-(8):

$$
\operatorname{Min} \sum_{(i, j) \in A} c_{i j} x_{i j}
$$

Sujeito a:

$$
\begin{gathered}
\sum_{(i, j) \in T} y_{i j}=p \\
\sum_{j \mid(i, j) \in A_{O}^{\prime}} x_{i j} \leq a_{i} \quad \forall i \in O \\
\sum_{i \mid(i, k) \in A} x_{i k}=\sum_{j \mid(k, j) \in A} x_{k j} \quad \forall k \in V \backslash\{O \cup D\}
\end{gathered}
$$
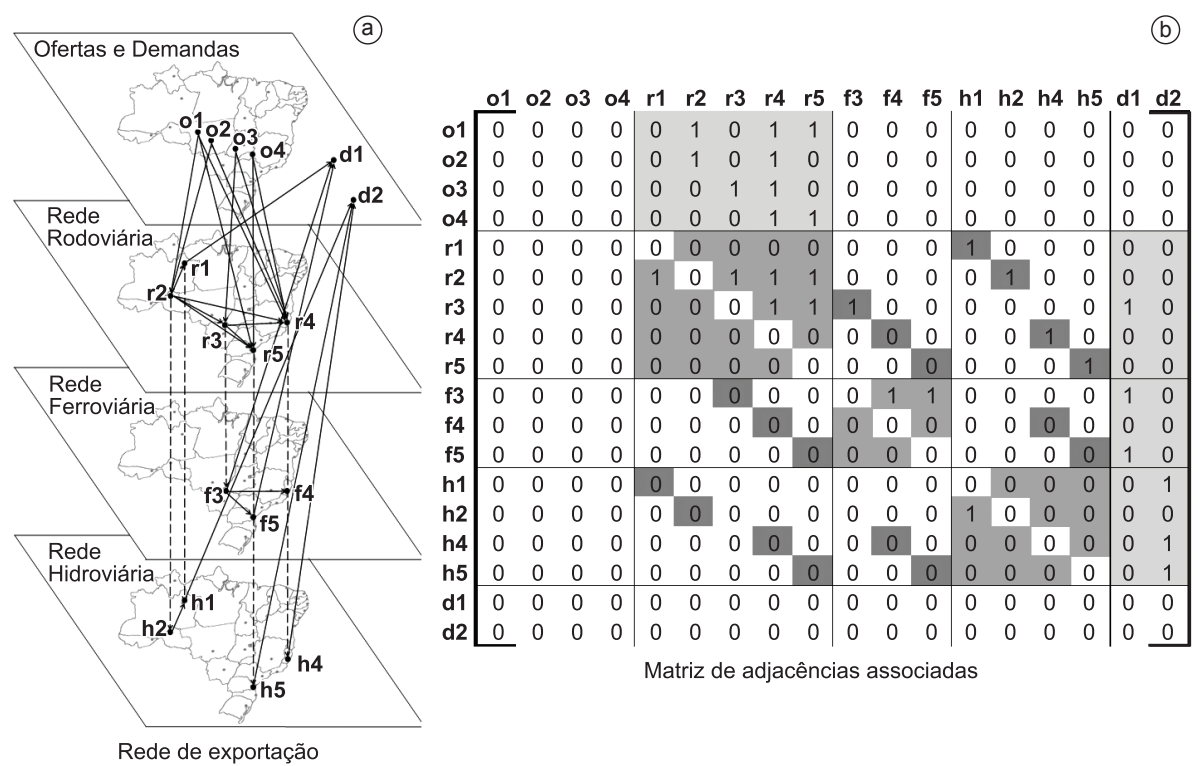

Figura 3. Exemplo de rede com $|O|=4,|D|=2,\left|V_{1}\right|=5,\left|V_{2}\right|=3$ e $\left|V_{3}\right|=4$. 


$$
\begin{gathered}
\sum_{i \mid(i, j) \in A_{1}^{\prime} \cup A_{2 D}^{\prime} \cup A_{3 D}^{\prime}} x_{i j}=b_{j} \quad \forall j \in D \\
x_{i j} \leq u_{i j} y_{i j} \quad \forall(i, j) \in T \\
x_{i j} \geq 0 \quad \forall(i, j) \in A \\
y_{i j} \in\{0,1\} \quad \forall(i, j) \in T
\end{gathered}
$$

A função objetivo (Equação 1) visa à minimização dos custos de transporte e transbordo, não considerando custos fixos de instalação para os terminais intermodais. A restrição da Equação 2 garante que exatamente $p$ terminais sejam instalados. As restrições das Equações 3-5 garantem as restrições de fluxo no sistema, se referindo na Equação 3 às quantidades ofertadas, na Equação 4 à conservação do fluxo nos nós intermediários e na Equação 5 ao atendimento da demanda. Na Equação 6, garante-se que só pode haver fluxo em um terminal intermodal se este for aberto e respeitadas as limitações de capacidade de transbordo. Finalmente, nas Equações 7 e 8 são definidos os domínios das variáveis, sendo as variáveis de fluxo não negativas e binárias as de abertura de terminais.

Observa-se que o modelo de fluxos acima pode ser visto como um modelo de localização multiníveis, em que cada nível corresponde ao fluxo de um terminal intermodal para outro. Pode ser mostrado que o modelo clássico de $p$-medianas é um caso particular desse modelo. Portanto, como já foi mostrado que o problema de $p$-medianas com $p$ variável é NP-difícil (DASKIN, 1995), isto implica que o problema aqui estudado também é NP-difícil.

\subsection{Algumas extensões para o modelo}

Algumas considerações adicionais podem ser facilmente incorporadas ao modelo, tais como a introdução de custos fixos para instalação dos terminais intermodais na função objetivo, bastando incluir um parâmetro $f_{i j}$, referente ao custo de instalação de um terminal intermodal em $(i, j),(i, j) \in T$ e substituir a

Equação 1 por Min $\sum_{(i, j) \in A} c_{i j} x_{i j}+\sum_{(i, j) \in T} f_{i j} y_{i j}$. Caso se deseje considerar restrições de capacidade para os fluxos nos arcos de transporte ferroviário e hidroviário, basta incluir canalizações das variáveis de fluxo $x_{i j} \leq w_{i j}, \forall(i, j) \in A_{2} \cup A_{3}$, associadas a estes arcos, em que $w_{i j}$ é a capacidade do arco $(i, j)$. Por se tratar de um problema voltado à exportação da soja, o modelo considera que o transbordo em um terminal intermodal ocorre sempre em uma única direção, como, por exemplo, do modal rodoviário para o ferroviário. Para permitir a inclusão de rotas de importação, é necessário que o fluxo no sistema seja bidirecional, bastando substituir a restrição (Equação 2) do modelo

pelas restrições $\sum_{(i, j) \in T} y_{i j}=2 p$ e $y_{i j}=y_{j i}, \forall(i, j) \in T$, de forma que o fluxo possa ocorrer em qualquer sentido dentro de um terminal intermodal.

\section{Resultados computacionais}

O modelo (Equações 1-8) foi implementado computacionalmente utilizando-se a linguagem de modelagem AMPL (FOURER; GAY; KERNIGHAN, 2002) e os testes foram realizados com dois softwares de otimização, o AMPL/CLPEX 11.1 e o software livre GNU GLPK 4.8. Nas seções que se seguem, são apresentados dois conjuntos de testes, contendo dados secundários e instâncias geradas aleatoriamente. Como plataforma computacional, utilizou-se um microcomputador Core2 Duo 2.0, 4 Gb RAM, sistema operacional Windows Vista Home Premium.

\subsection{Testes com dados secundários}

Com o propósito de verificar a coerência do modelo e discutir algumas possibilidades de análise dos resultados, foram realizados alguns experimentos com dados do relatório "Corredores estratégicos de desenvolvimento: alternativas de escoamento de soja para exportação" (GRUPO..., 2001), no qual dois cenários distintos, 2000 e 2015, foram analisados. São considerados $m=3,|O| \leq 15,|D|=2$ e $20 \leq|T| \leq 39$. Os testes no GLPK foram concluídos em até 17,1 segundos, demonstrando a possibilidade do uso de um software livre de otimização para resolução de problemas desse porte em tempo computacional aceitável.

No primeiro cenário, as rotas foram definidas segundo a configuração física do sistema em 2000, com 11 regiões produtoras de soja. No segundo, foram consideradas modificações previstas naquele ano para 2015, o deslocamento de parte da demanda de Rotterdam para Shangai, aumento na produção e a inclusão de 4 novas regiões de oferta. Como o referido relatório não apresenta dados de capacidade, considerou-se $\sum_{j} b_{j}, j \in D$ como limitante para o fluxo nos terminais intermodais. Para cada cenário, foi realizado um conjunto de testes, variando-se $p$ a partir de 0 , situação em que nenhum terminal intermodal é instalado, até o número máximo de candidatos $|T|$. Dessa forma, obtêm-se o número e a localização ótima de terminais intermodais e os fluxos que minimizam os custos de transporte e transbordo. As siglas e os nomes das localidades consideradas se encontram na Tabela 2.

Na Rede GEIPOT 2000, são necessários $p=4$ para a obtenção de uma solução factível, devido à inexistência de rotas diretas de escoamento. A Figura 4a mostra a 
variação dos custos de transporte e transbordo com o aumento de $p$, obtendo-se o custo mínimo com $p=15$ e o padrão de fluxos mostrado na Figura $4 \mathrm{~b}$. Para $p=5$, um terminal rodo-ferroviário é indicado em Uberlândia e, quando $p=6$, este terminal dá lugar a de Porto Velho e Itacoatiara, permitindo o uso dessa rota rodo-hidroviária para escoamento da oferta de
Campo Novo do Parecis. A partir de $p=8$, o terminal rodo-marítimo de Santos não é aberto, permitindo chegadas a esse porto somente por ferrovia. Com $p=15$, obseva-se que, apesar do uso de muitas rotas intermodais, as ofertas de Sorriso, Campo Novo do Parecis e Dourados percorrem grandes trechos por rodovias. Além disso, há concentração de fluxo na

Tabela 2. Siglas e nomes das localidades consideradas nas redes baseadas em GEIPOT (GRUPO..., 2001).

\begin{tabular}{|c|c|c|c|}
\hline Sigla & Localidade & Sigla & Localidade \\
\hline AAR & Alto Araguaia $(\mathrm{MT})^{\mathrm{t}}$ & NXA & Nova Xavantina $(\mathrm{MT})^{\mathrm{o}, \mathrm{t}}$ \\
\hline ATA & Alto Taquari $(\mathrm{MT})^{\mathrm{t}}$ & PAL & Palmas $(\mathrm{TO})^{\circ}$ \\
\hline BAL & Balsas (MA) ${ }^{\circ}$ & PAR & Paranaguá $(\mathrm{PR})^{\mathrm{t}}$ \\
\hline BAU & Bauru $(\mathrm{SP})^{\mathrm{t}}$ & PDL & Primavera do Leste $(\mathrm{MT})^{\circ}$ \\
\hline BGA & Barra do Garças $(\mathrm{MT})^{\mathrm{t}}$ & PGR & Ponta Grossa $(\mathrm{PR})^{\mathrm{t}}$ \\
\hline BOT & Botucatu $(\mathrm{SP})^{\mathrm{t}}$ & PSA & Porto de Santana (AP) ${ }^{t}$ \\
\hline CAS & Cascavel $(\mathrm{PR})^{\mathrm{t}}$ & RON & Rondonópolis (MT) ${ }^{o, t}$ \\
\hline CER & Ceres $(\mathrm{GO})^{\mathrm{t}}$ & RVE & Rio Verde $(\mathrm{GO})^{\mathrm{o}, \mathrm{t}}$ \\
\hline CDS & Chapadão do Sul (MS) $)^{\mathrm{o}, \mathrm{t}}$ & SAN & Santos $(\mathrm{SP})^{\mathrm{t}}$ \\
\hline CGR & Campo Grande (MS) $)^{o, t}$ & SOR & Sorriso $(\mathrm{MT})^{\mathrm{o}}$ \\
\hline $\mathrm{CNP}$ & Campo Novo do Parecis (MT) ${ }^{\circ}$ & SSI & São Simão $(G O)^{t}$ \\
\hline CRA & Cachoeira Rasteira $(\mathrm{MT})^{\mathrm{t}}$ & STA & Santarém $(\mathrm{PA})^{\mathrm{t}}$ \\
\hline CUI & Cuiabá $(\mathrm{MT})^{\mathrm{t}}$ & UBE & Uberlândia $(\mathrm{MG})^{\mathrm{o}, \mathrm{t}}$ \\
\hline DOU & Dourados $(\mathrm{MS})^{\mathrm{o}, \mathrm{t}}$ & URU & Uruçuí (PI) ${ }^{\circ}$ \\
\hline EST & Estreito $(\mathrm{MA})^{\mathrm{t}}$ & VDC & Vila do Conde $(\mathrm{PA})^{\mathrm{t}}$ \\
\hline GOI & Goiânia (GO) $)^{\mathrm{o}, \mathrm{t}}$ & VIL & Vilhena (RO) ${ }^{\circ}$ \\
\hline ITB & Itaituba $(\mathrm{PA})^{\mathrm{t}}$ & VIT & Vitória $(\mathrm{ES})^{\mathrm{t}}$ \\
\hline ITC & Itacoatiara $(\mathrm{AM})^{\mathrm{t}}$ & XAM & Xambioá $(\mathrm{TO})^{\mathrm{t}}$ \\
\hline ITG & Itaguaí $(\mathrm{RJ})^{\mathrm{t}}$ & ROTTERDAM $^{\mathrm{d}}$ & \\
\hline ITQ & Itaqui $(\mathrm{MA})^{\mathrm{t}}$ & SHANGAI $^{\mathrm{d}}$ & \\
\hline
\end{tabular}

${ }^{\circ}$ Pontos de oferta, ${ }^{\text {t}}$ Candidatos à instalação de terminal intermodal, ${ }^{\mathrm{d}}$ Pontos de demanda.

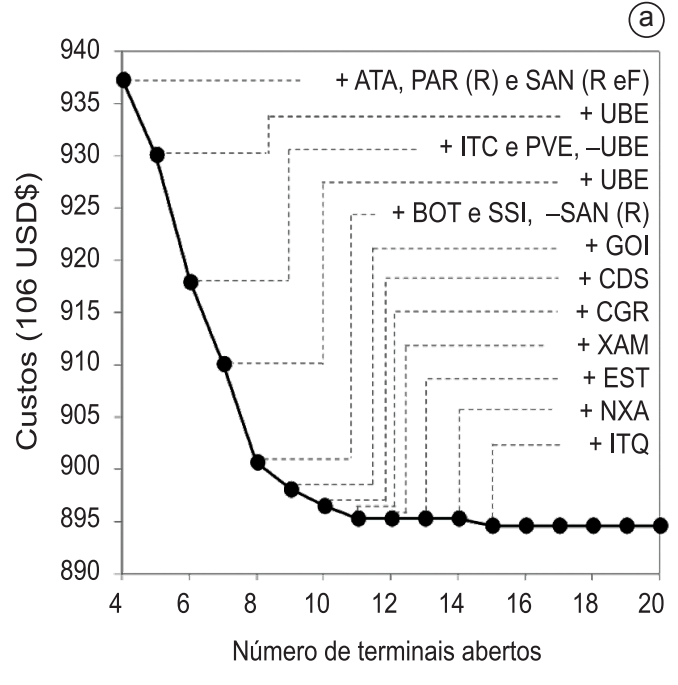

Custos $\times$ número de terminais em 2000

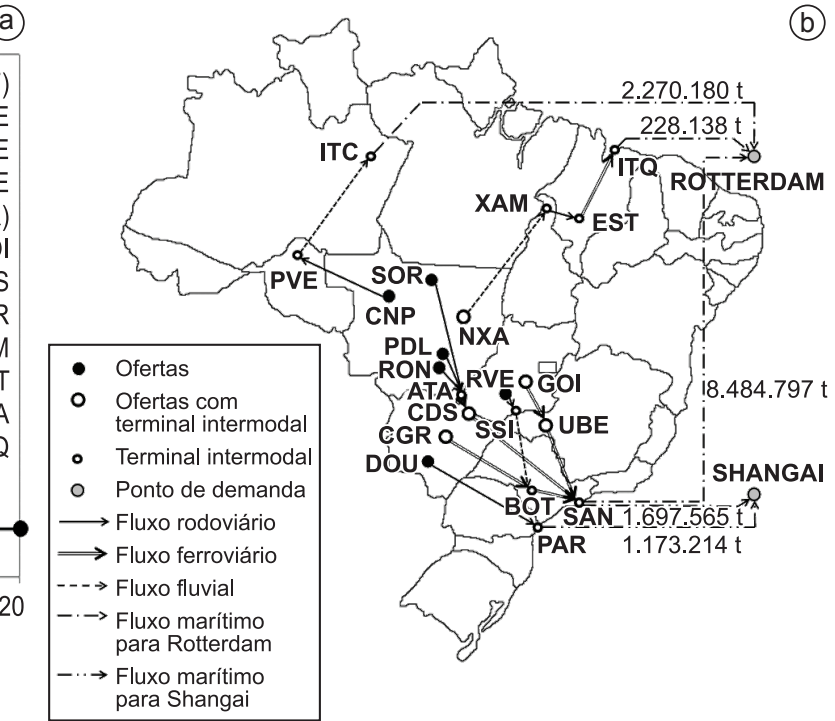

Fluxos em 2000 com 15 terminais

Figura 4. Resultados para o cenário GEIPOT 2000. 
ferrovia entre Alto Taquari e Santos, que transporta 5.420.886 t, que representam $37,77 \%$ do total, e também no porto de Santos, que absorve $10.682 .544 \mathrm{t}$ ou $74,42 \%$ de toda a soja exportada.

Na Figura 5a, tem-se a variação de custos com o número de terminais instalados e na Figura $5 b$ descreve-se o fluxo de custo mínimo para a rede GEIPOT 2015, obtido com $p=17$ terminais intermodais. Em relação a 2000, observa-se um melhor aproveitamento do potencial hidroviário no escoamento da produção das regiões Norte e Nordeste, incluindo-se as 4 novas regiões de oferta. O modal ferroviário também mostra maior integração, absorvendo toda a produção de Goiás, Mato Grosso do Sul e Minas Gerais. É perceptível a redução no uso do transporte rodoviário, de custo relativamente mais elevado. Grandes volumes continuam fluindo pelo porto de Santos, representando cerca de $46,31 \%$ do total, embora o fluxo na ferrovia entre Alto Taquari e Santos tenha se reduzido a $14,62 \%$ da soja exportada.

Com o intuito de estudar alguns gargalos da rede, um terceiro cenário foi analisado, com dados de produção de soja em 2008 (INSTITUTO..., 2010), cuja relação com as produções de 2000 e 2015 são mostradas na Figura 6. As demais características do sistema foram mantidas como descritas em GEIPOT (GRUPO..., 2001). De acordo com a ANTAQ (AGÊNCIA..., 2009), o porto de Santos tem capacidade de embarque de cereais entre 600 e $1.500 \mathrm{t} / \mathrm{h}$, o que permitiria a exportação de até 13.140 .000 t/ano. Foram realizados 170 testes, variando-se $p=6,7$, $8, \ldots, 39$, impondo-se capacidades em Santos de 600, $750,900,1.050$ e $1.500 \mathrm{t} / \mathrm{h}$, e limitações de fluxos nos portos do Sudeste e Sul com base em dados de movimentação de soja em 2008 (AGÊNCIA..., 2009).

À medida que a capacidade de Santos decresce, os custos crescem em até $3,52 \%$, pois ocorrem desvios

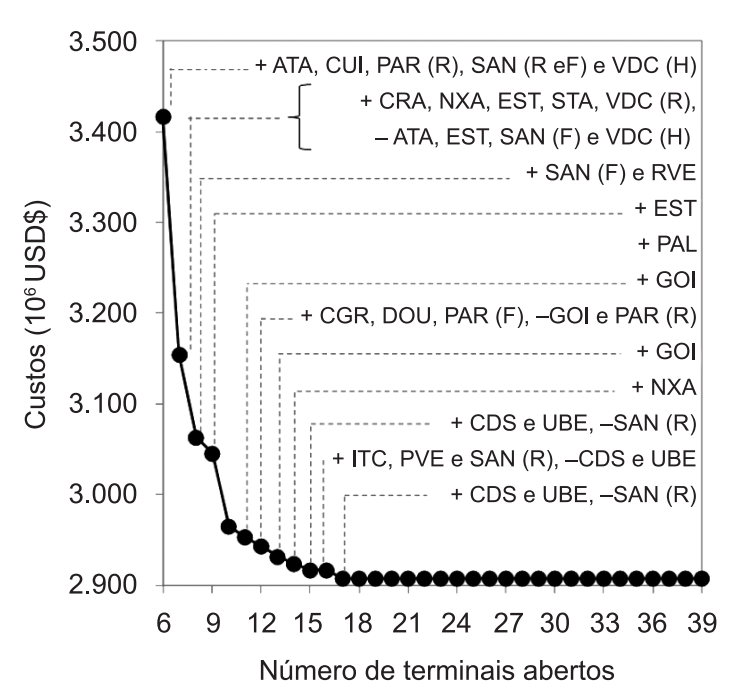

Custos $\times$ número de terminais em 2015

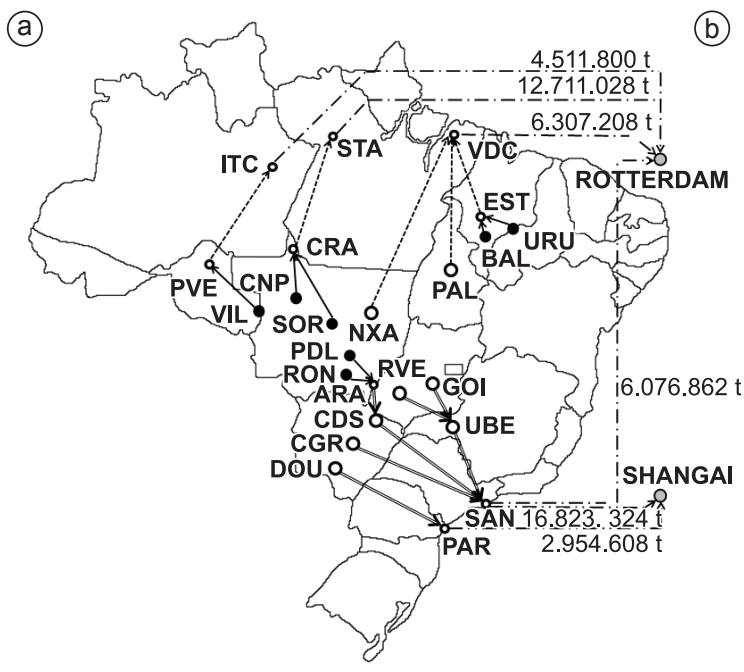

Fluxos em 2015 com 17 terminais

Figura 5. Resultados para o cenário GEIPOT 2015.

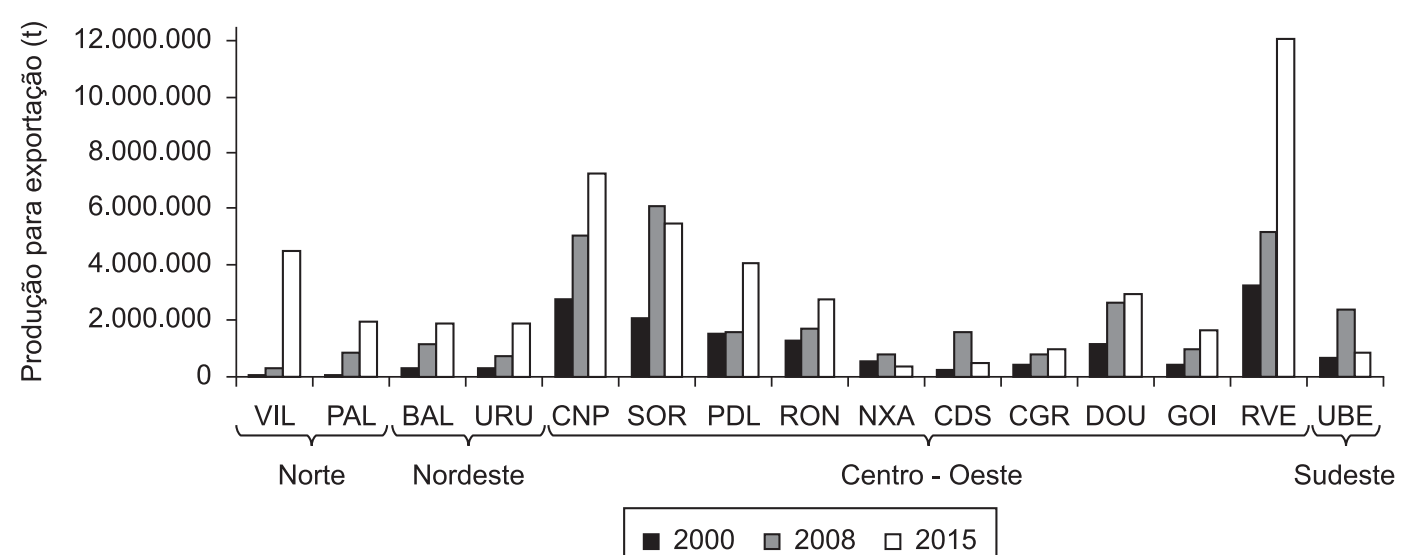

Figura 6. Distribuição da produção de soja para exportação. 
nos fluxos para outros portos, utilizando rotas de custo mais elevado. Com capacidade de $1.500 \mathrm{t} / \mathrm{h}$, o porto de Santos já se encontra congestionado, porém o padrão de fluxos é mantido como na Figura $5 \mathrm{~b}$, à exceção de Primavera do Leste, que tem 30,52\% da produção desviada para Nova Xavantina. Com $1.050 \mathrm{t} / \mathrm{h}$, as produções de Primavera do Leste e Rondonópolis são completamente desviadas para Nova Xavantina, enquanto a soja de Campo Grande usa a rota rodo-ferroviária que passa por Ponta Grossa até Paranaguá. Se a capacidade de Santos for reduzida para 900 t/h, são necessários $p=19$ para a obtenção dos fluxos de custo mínimo, como mostrado na Figura 7a. Além das modificações já citadas, a soja de Goiás e Minas Gerais é exportada por Vitória. Com 600 t/h, como mostrado na Figura 7b, ocorre congestionamento nos portos de Santos e Vitória. Em consequência, a produção de Chapadão do Sul é exportada pelo porto de Itaguaí e parte da soja de Rio Verde é desviada para o porto de Vila do Conde, passando pelo terminal rodo-hidroviário de Barra do Garças. Embora as quantidades exportadas pelos portos do Norte sejam elevadas, não foi possível estudar o congestionamento nesses portos, devido à dificuldade de obtenção de dados.

\subsection{Testes com instâncias geradas aleatoriamente}

Com o propóstito de avaliar o desempenho do modelo, que é NP-difícil, em relação ao tempo computacional necessário à obtenção da solução ótima, foram criadas 160 instâncias, geradas a partir de um programa de computador escrito em Dev C++ v.4.9.9.2. Os vértices dos conjuntos $O, D, V_{m}$, $m=1,2,3$, foram sorteados segundo uma distribuição uniforme dentro do limite da sequência de números aleatórios do software, da mesma forma que os parâmetros $a_{i j}, b_{i j}$ e $u_{i j}$, porém mantendo-se $\sum_{i} a_{i}=\sum_{j} b_{j}$. Os custos $c_{i j}$, consideram valores médios de frete (SISTEMA..., 2009) nos trechos viários, multiplicados pela respectiva distância euclidiana, assumindo-se um valor fixo para os custos de transbordo.

Ao todo foram realizados mais de 3.500 testes, conduzidos variando-se o valor de $p$, como com os dados secundários, e observando-se alguns padrões de comportamento. Na Figura 8a, observa-se que antes da obtenção dos fluxos de custo mínimo, ou para $p<p^{*}$, os tempos de processamento são elevados e se distribuem aleatoriamente, enquanto para $p \geq p^{*}$, os tempos de processamento são baixos e se distribuem de forma uniforme. Assim, os resultados dos testes foram computados apenas até $p=p^{*}+1,<|T|$.

Quando se analisam as variações nos valores da função objetivo e do GAP da relaxação linear com a variação de $p$, obtêm-se funções monotonicamente não crescentes, que se estabilizam quando $p \geq p$, como mostrado nas Figuras 8b, c. O GAP foi definido como $\frac{f o(p)-f o(R L)}{f_{o}(p)}$, em que $f o(p)$ e $f o(R L)$ são os valores das funções objetivo do problema original e da relação linear, respectivamente. Quanto mais restritos forem os fluxos nos terminais intermodais, maior o GAP quando $p=1$, sendo sempre nulo para $p \geq p^{*}$.

Na Figura 8d, tem-se um exemplo da exploração da árvore de branch-and-cut, com um GAP inicial de $94,23 \%$ no nó-raiz, que cai rapidamente para 0,91\% já no centésimo nó. Pelo detalhe da figura, percebe-se que o maior esforço computacional se concentra em provar a otimalidade da solução e não em encontrar uma solução ótima, o que só ocorreu

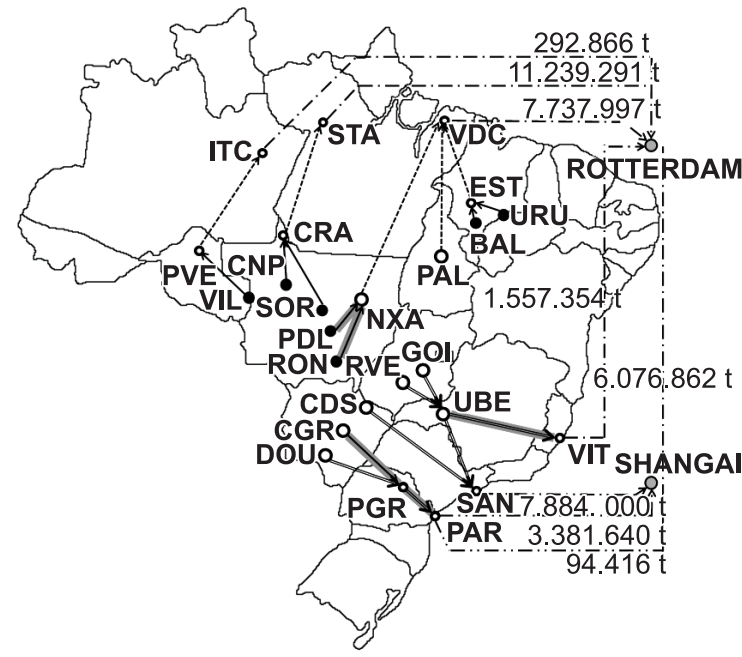

Capacidade operacional $=900 \mathrm{t} / \mathrm{h}$

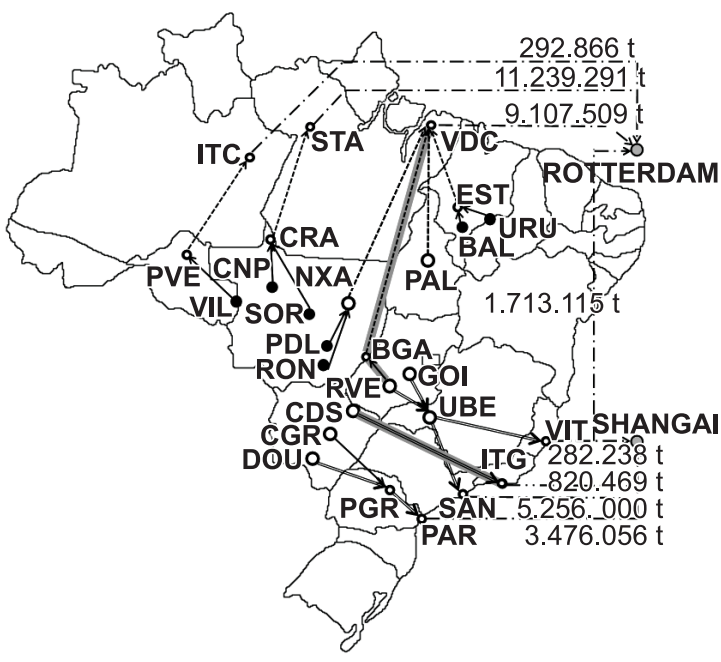

Capacidade operacional $=600 \mathrm{t} / \mathrm{h}$

Figura 7. Desvios nos fluxos ótimos ocasionados pelo congestionamento do porto de Santos. 


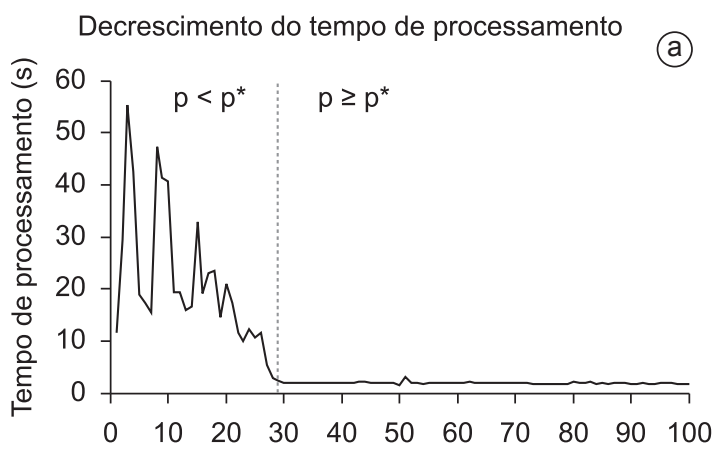

Número de terminais intermodais abertos

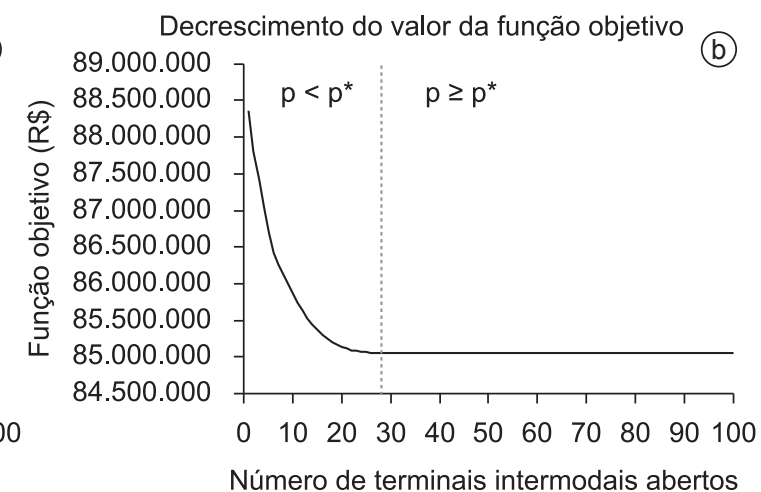

Decrescimento do GAP de otimalidade

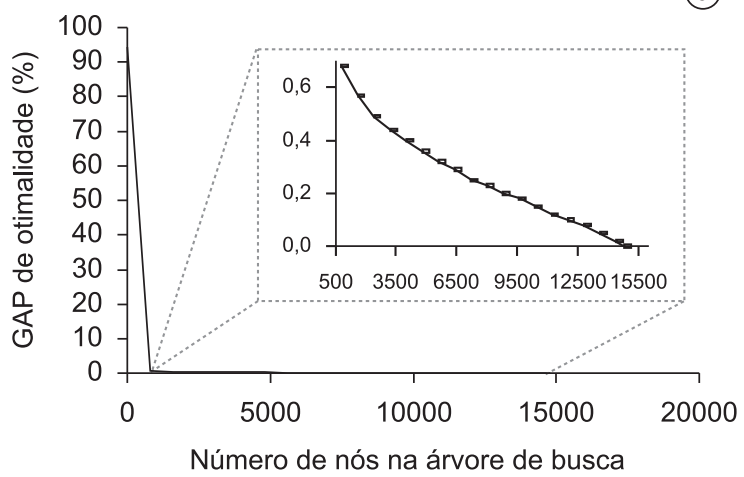

Figura 8. Comportamentos observados para o modelo proposto.

Tabela 3. Comparação de desempenho (s) entre o AMPL/CPLEX e o GLPK com $|T|=50$.

\begin{tabular}{|c|c|c|c|c|c|c|c|c|c|}
\hline \multirow[t]{2}{*}{$|O|=|D|$} & \multirow[t]{2}{*}{ Testes } & \multicolumn{4}{|c|}{ Tempos obtidos no AMPL/CPLEX } & \multicolumn{4}{|c|}{ Tempos obtidos no GLPK } \\
\hline & & Médio & D. Padrão & Menor & Maior & Médio & D. Padrão & Menor & Maior \\
\hline 25 & 14 & 0,203 & 0,078 & 0,078 & 0,296 & 5,729 & 5,548 & 0,200 & 13,600 \\
\hline 50 & 13 & 0,377 & 0,199 & 0,093 & 0,826 & 7,185 & 7,374 & 0,300 & 21,000 \\
\hline 75 & 14 & 0,392 & 0,119 & 0,171 & 0,530 & 9,471 & 8,816 & 0,400 & 26,900 \\
\hline 100 & 18 & 0,879 & 0,484 & 0,202 & 1,810 & 3,756 & 2,753 & 0,700 & 8,300 \\
\hline 125 & 15 & 0,881 & 0,437 & 0,199 & 1,716 & 15,487 & 15,365 & 0,700 & 49,600 \\
\hline 150 & 18 & 1,233 & 0,549 & 0,368 & 2,137 & 19,794 & 21,512 & 1,100 & 67,000 \\
\hline 175 & 19 & 1,525 & 0,674 & 0,312 & 2,812 & 1,525 & 0,674 & 0,312 & 414,000 \\
\hline 200 & 18 & 1,320 & 0,479 & 0,534 & 2,199 & 19,339 & 15,220 & 1,600 & 47,000 \\
\hline 225 & 15 & 1,383 & 0,754 & 0,280 & 2,402 & 34,847 & 35,379 & 1,200 & 95,000 \\
\hline 250 & 17 & 1,851 & 0,838 & 0,561 & 3,229 & 28,741 & 36,679 & 2,400 & 108,500 \\
\hline 275 & 14 & 1,962 & 1,257 & 0,343 & 4,664 & 26,636 & 25,640 & 1,800 & 69,300 \\
\hline 300 & 13 & 2,482 & 2,047 & 0,374 & 7,410 & 7,100 & 6,440 & 1,700 & 21,000 \\
\hline 325 & 17 & 2,994 & 1,603 & 0,499 & 6,552 & 70,647 & 73,182 & 2,300 & 219,700 \\
\hline 350 & 17 & 3,806 & 2,994 & 0,452 & 9,594 & 23,941 & 22,554 & 2,700 & 65,200 \\
\hline 375 & 17 & 4,972 & 2,914 & 0,734 & 11,609 & 309,759 & 292,123 & 2,800 & 843,600 \\
\hline 400 & 20 & 4,862 & 4,074 & 0,778 & 13,821 & 246,115 & 274,409 & 3,800 & 887,500 \\
\hline 425 & 17 & 4,282 & 2,529 & 0,717 & 10,420 & 690,506 & 719,185 & 3,261 & $2.243,700$ \\
\hline 450 & 25 & 5,675 & 3,641 & 0,717 & 12,261 & 665,596 & 575,928 & 4,800 & $1.457,200$ \\
\hline 475 & 17 & 7,732 & 4,411 & 0,702 & 13,197 & 416,376 & 421,564 & 4,500 & $1.208,300$ \\
\hline 500 & 21 & 7,667 & 5,513 & 0,904 & 19,188 & 262,252 & 251,479 & 5,200 & 680,800 \\
\hline
\end{tabular}


após a abertura de 14.800 nós. Esse comportamento indica que heurísticas com critério de parada baseado em tempo de processamento podem gerar bons resultados para o problema.

A seguir, o desempenho relativo entre os softwares AMPL/CPLEX e GLPK foi avaliado, obtendo-se os resultados mostrados na Tabela 3 , em que $|T|=50$. Observa-se que o desempenho do AMPL/CPLEX foi muito superior, chegando a ser 215,33 vezes mais rápido, no caso da rede com $|O|=|D|=425$. Quando se aumentam os conjuntos $O$ e $D$, observa-se um crescimento exponencial dos tempos de processamento, como mostrado na Figura 9.

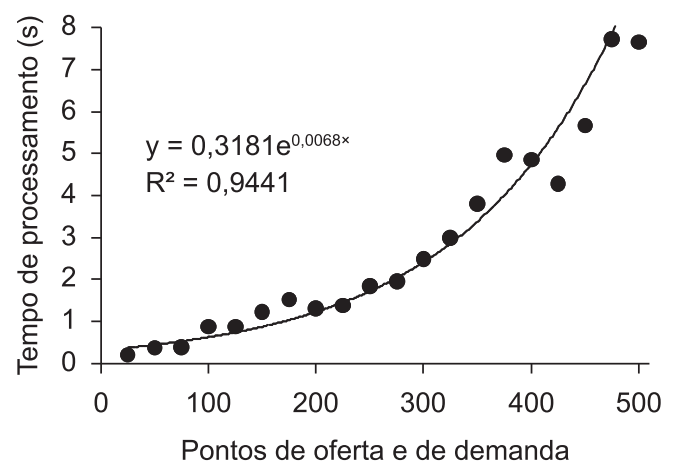

- AMPL/CPLEX — Exponencial (AMPL/CPLEX)
Como os tempos médios de processamento no GLPK foram bastante razoáveis, poucas vezes ultrapassando 10 minutos, outros experimentos foram realizados, com $|T|=100$. Nesses testes, os tempos de processamento no GLPK se tornaram excessivamente altos, indicando que a sua utilização com redes dessa ordem de grandeza não é indicada. Os testes foram interrompidos ao se obter um tempo de 20.171,3 segundos, o que equivale a 5,6 horas, para a instalação de $p=10$, em uma rede com $|O|=|D|=125$. Os resultados para esses testes são mostrados na Tabela 4. As curvas de crescimento do tempo de processamento com o aumento de $O$ e

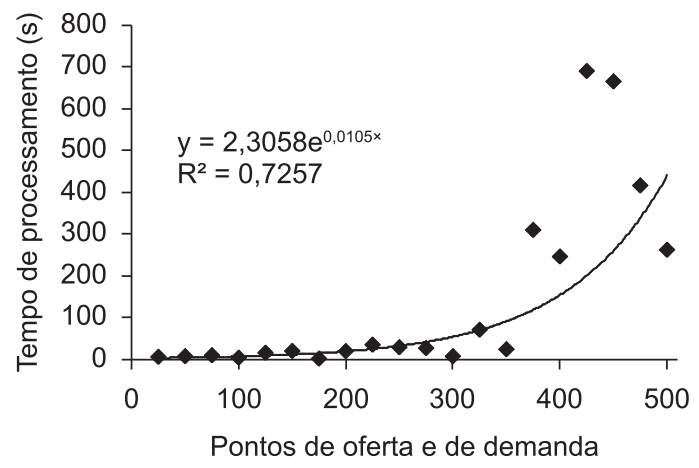

- GLPK — Exponencial (GLPK)

Figura 9. Tempo de processamento (s) no AMPL/CPLEX e no GLPK com $|T|=50$.

Tabela 4. Comparação entre o AMPL/CPLEX e o GLPK com $|\mathrm{T}|=100$.

\begin{tabular}{|c|c|c|c|c|c|c|c|c|c|}
\hline \multirow[t]{2}{*}{$|O|=|D|$} & \multirow[t]{2}{*}{ Testes } & \multicolumn{4}{|c|}{ Tempos obtidos no AMPL/CPLEX } & \multicolumn{4}{|c|}{ Tempos obtidos no GLPK } \\
\hline & & Médio & D. Padrão & Menor & Maior & Médio & D. Padrão & Menor & Maior \\
\hline 25 & 21 & 2,207 & 1,314 & 0,327 & 4,807 & 125,333 & 125,005 & 0,500 & 425,500 \\
\hline 50 & 18 & 2,467 & 1,531 & 0,374 & 4,602 & 232,450 & 323,802 & 0,800 & $1.017,900$ \\
\hline 75 & 20 & 4,641 & 4,674 & 0,375 & 19,906 & 188,960 & 276,368 & 1,200 & 874,300 \\
\hline 100 & 20 & 1,660 & 0,672 & 0,483 & 2,652 & 44,070 & 58,468 & 1,400 & 186,500 \\
\hline 125 & 26 & 6,078 & 5,979 & 0,669 & 22,600 & $7.161,880$ & $7.484,400$ & 15,400 & $20.171,300$ \\
\hline
\end{tabular}
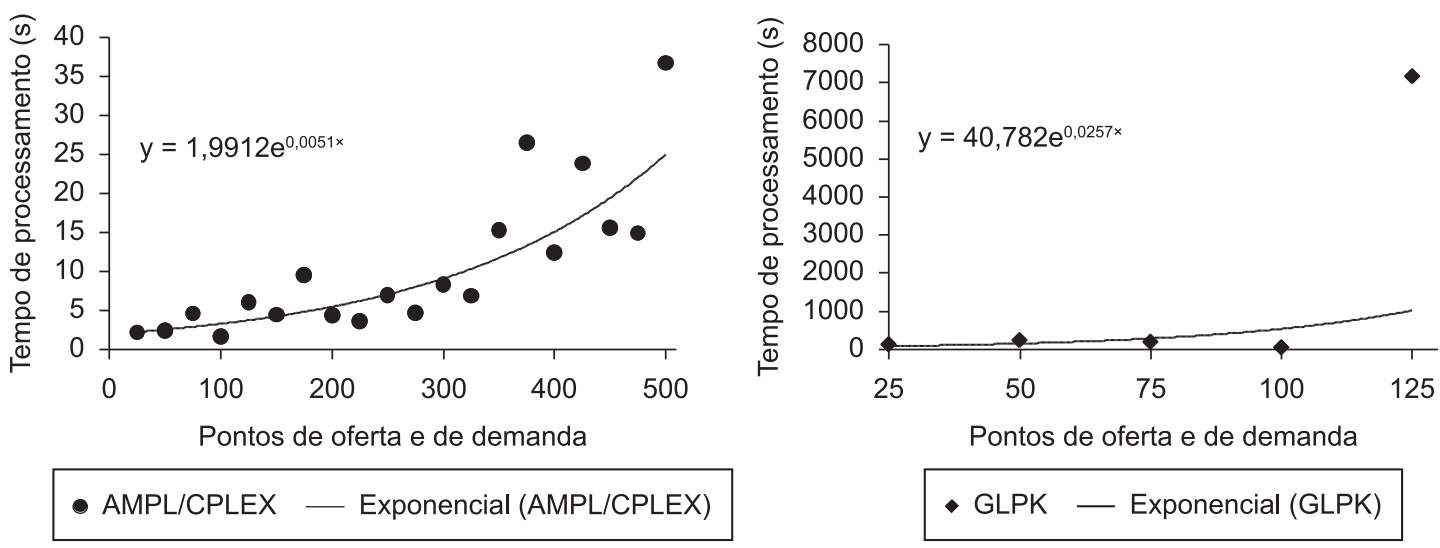

Figura 10. Tempo de processamento (s) no AMPL/CPLEX e no GLPK com $|T|=100$. 
Tabela 5. Tempos médios (s) de processamento no AMPL/CPLEX com a variação de $|T|$.

\begin{tabular}{|c|c|c|c|c|c|c|c|c|}
\hline \multirow[t]{2}{*}{$|O|=|D|$} & \multicolumn{2}{|c|}{$|T|=\mathbf{5 0}$} & \multicolumn{2}{|c|}{$|T|=100$} & \multicolumn{2}{|c|}{$|T|=150$} & \multicolumn{2}{|c|}{$|T|=200$} \\
\hline & Testes & Média & Testes & Média & Testes & Média & Testes & Média \\
\hline 25 & 14 & 0,203 & 21 & 2,207 & 16 & 2,408 & 24 & 15,501 \\
\hline 50 & 13 & 0,357 & 18 & 2,467 & 23 & 9,076 & 27 & 19,749 \\
\hline 75 & 14 & 0,392 & 20 & 4,641 & 29 & 14,056 & 34 & 123,641 \\
\hline 100 & 18 & 0,843 & 20 & 1,660 & 27 & 13,370 & 30 & 20,367 \\
\hline 125 & 15 & 0,929 & 26 & 6,078 & 30 & 11,592 & 36 & 39,735 \\
\hline 150 & 18 & 1,439 & 27 & 4,446 & 30 & 11,738 & 42 & $1.953,840$ \\
\hline 175 & 19 & 1,525 & 26 & 9,507 & 30 & 7,867 & 41 & 74,694 \\
\hline 200 & 18 & 1,492 & 22 & 4,440 & 39 & 15,986 & 54 & 47,537 \\
\hline 225 & 15 & 1,462 & 26 & 3,683 & 38 & 37,214 & 40 & 732,631 \\
\hline 250 & 17 & 2,059 & 25 & 6,926 & 42 & 235,966 & 44 & 125,159 \\
\hline 275 & 14 & 1,962 & 29 & 4,667 & 35 & 11,460 & 51 & 267,883 \\
\hline 300 & 13 & 2,269 & 27 & 8,266 & 50 & 138,070 & 51 & 162,221 \\
\hline 325 & 17 & 2,994 & 29 & 6,870 & 34 & 45,907 & 55 & 416,244 \\
\hline 350 & 17 & 3,619 & 28 & 15,246 & 33 & 13,027 & 58 & $1.683,755$ \\
\hline 375 & 17 & 4,972 & 30 & 26,490 & 39 & 16,023 & 53 & 113,255 \\
\hline 400 & 20 & 4,862 & 26 & 12,141 & 28 & 90,044 & 46 & 196,285 \\
\hline 425 & 17 & 3,740 & 28 & 23,082 & 43 & 29,953 & 47 & 127,445 \\
\hline 450 & 25 & 5,675 & 32 & 15,578 & 47 & 100,582 & 55 & 485,757 \\
\hline 475 & 17 & 7,732 & 33 & 14,911 & 41 & 253,013 & 51 & 902,661 \\
\hline 500 & 21 & 7,104 & 32 & 17,879 & 46 & 83,935 & 45 & 334,211 \\
\hline
\end{tabular}

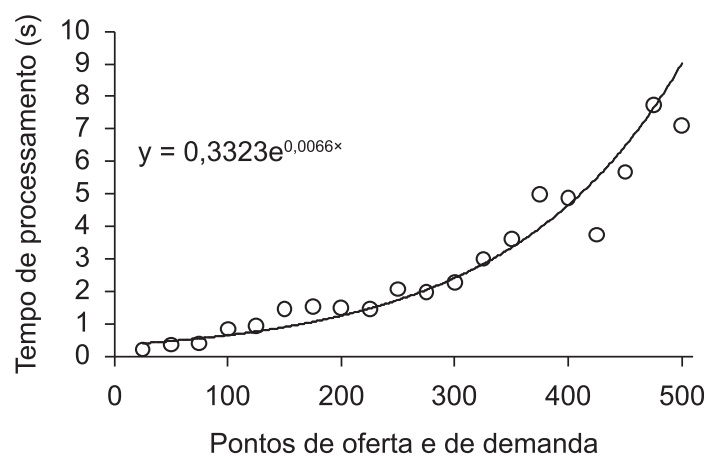

$\circ|\mathrm{T}|=50$ Exponencial $(|\mathrm{T}|=50)$

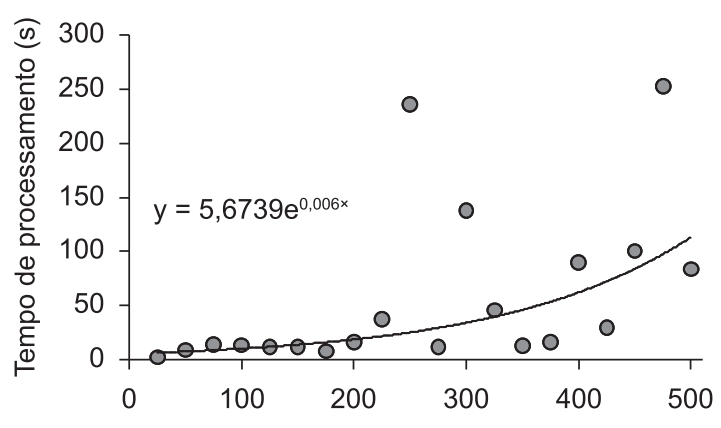

Pontos de oferta e de demanda

○ $|\mathrm{T}|=150$ Exponencial $(|\mathrm{T}|=150)$

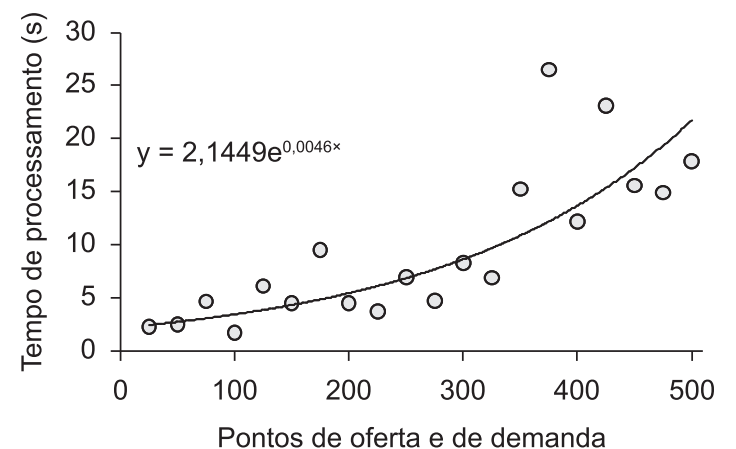

Pontos de oferta e de demanda
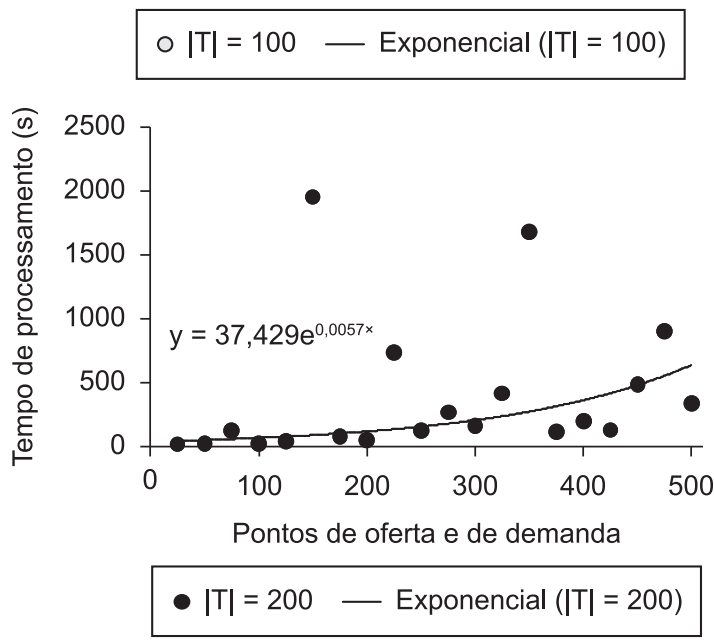

Figura 11. Tempo de processamento (s) no AMPL/CPLEX com $|T|=50,100,150$ e 200. 
$D$ são apresentadas na Figura 10, cujos testes foram concluídos apenas com o AMPL/CPLEX.

Como os testes com o AMPL/CPLEX apresentaram bons resultados, o seu desempenho foi medido ainda em relação ao crescimento do número de variáveis binárias do problema, isto é, o aumento de $|T|$, e quanto à inclusão de variáveis não negativas, pela adição de elementos aos conjuntos $O$ e $D$. No primeiro caso, foi possível obter tempos de processamento razoáveis, de até 1.953,40 segundos ou 0,543 horas em média, variando-se $|T|$ de 50 a 200 , em intervalos de 50, como mostrado na Tabela 5. Embora os desvios observados sejam altos, chegando a 12.440,08 segundos, o que levou à necessidade, no pior caso, de 22,4 horas de processamento, é possível afirmar que as adaptações realizadas no modelo permitem que se utilize o AMPL/CPLEX para resolver problemas em que se tem até $|T|=200$, ou seja, 200 variáveis binárias. $\mathrm{O}$ crescimento do tempo computacional necessário à obtenção da solução ótima também é exponencial, como pode ser verificado na Figura 11, em que se

Tabela 6. Tempos de processamento (s) no AMPL/CPLEX com o aumento de $|O|$ e $|D|$.

\begin{tabular}{|c|c|c|c|c|c|c|c|c|c|c|}
\hline \multirow[t]{2}{*}{$|O|=|D|$} & \multicolumn{5}{|c|}{$|T|=\mathbf{5 0}$} & \multicolumn{5}{|c|}{$|T|=100$} \\
\hline & Testes & Médio & D. Padrão & Menor & Maior & Testes & Médio & D. Padrão & Menor & Maior \\
\hline 100 & 18 & 0,879 & 0,484 & 0,202 & 1,810 & 20 & 1,660 & 0,672 & 0,483 & 4,807 \\
\hline 200 & 18 & 1,320 & 0,479 & 0,534 & 2,199 & 22 & 4,602 & 3,148 & 0,702 & 14,958 \\
\hline 300 & 13 & 2,482 & 2,047 & 0,374 & 7,410 & 27 & 8,311 & 6,409 & 1,172 & 21,093 \\
\hline 400 & 20 & 5,024 & 3,993 & 0,639 & 13,821 & 26 & 12,444 & 6,267 & 1,890 & 24,796 \\
\hline 500 & 21 & 7,667 & 5,513 & 0,904 & 19,188 & 34 & 17,985 & 18,846 & 2,015 & 85,375 \\
\hline 600 & 25 & 4,742 & 3,026 & 0,904 & 11,762 & 32 & 20,359 & 39,068 & 3,140 & 142,046 \\
\hline 700 & 22 & 15,902 & 14,363 & 1,060 & 49,686 & 34 & 41,568 & 56,994 & 2,984 & 254,343 \\
\hline 800 & 19 & 9,544 & 8,755 & 1,248 & 32,526 & 39 & 167,571 & 201,107 & 4,265 & 679,015 \\
\hline 900 & 24 & 44,655 & 56,843 & 1,544 & 196,466 & 39 & 105,558 & 120,974 & 4,609 & 417,343 \\
\hline 1.000 & 23 & 46,134 & 32,858 & 1,622 & 99,465 & 40 & 419,630 & $1.557,341$ & 5,007 & $9.846,996$ \\
\hline 1.100 & 23 & 105,506 & 138,415 & 2,308 & 444,678 & 39 & 316,864 & 437,238 & 5,625 & $1.419,385$ \\
\hline 1.200 & 21 & 64,878 & 75,049 & 2,308 & 262,438 & 40 & 272,832 & 396,596 & 5,812 & $2.280,753$ \\
\hline 1.300 & 18 & 62,776 & 69,570 & 2,620 & 201,864 & 43 & 583,144 & $1.553,248$ & 6,828 & $9.656,481$ \\
\hline 1.400 & 22 & 31,300 & 19,950 & 2,511 & 71,198 & 34 & $8.539,556$ & $6.122,434$ & 101,000 & $21.002,337$ \\
\hline 1.500 & 23 & 37,410 & 34,517 & 3,135 & 117,858 & 44 & $1.937,665$ & $2.406,781$ & 8,390 & $4.724,403$ \\
\hline 1.600 & 25 & 104,847 & 110,479 & 4,305 & 307,897 & 40 & $1.662,684$ & $2.880,034$ & 9,250 & $11.862,579$ \\
\hline
\end{tabular}

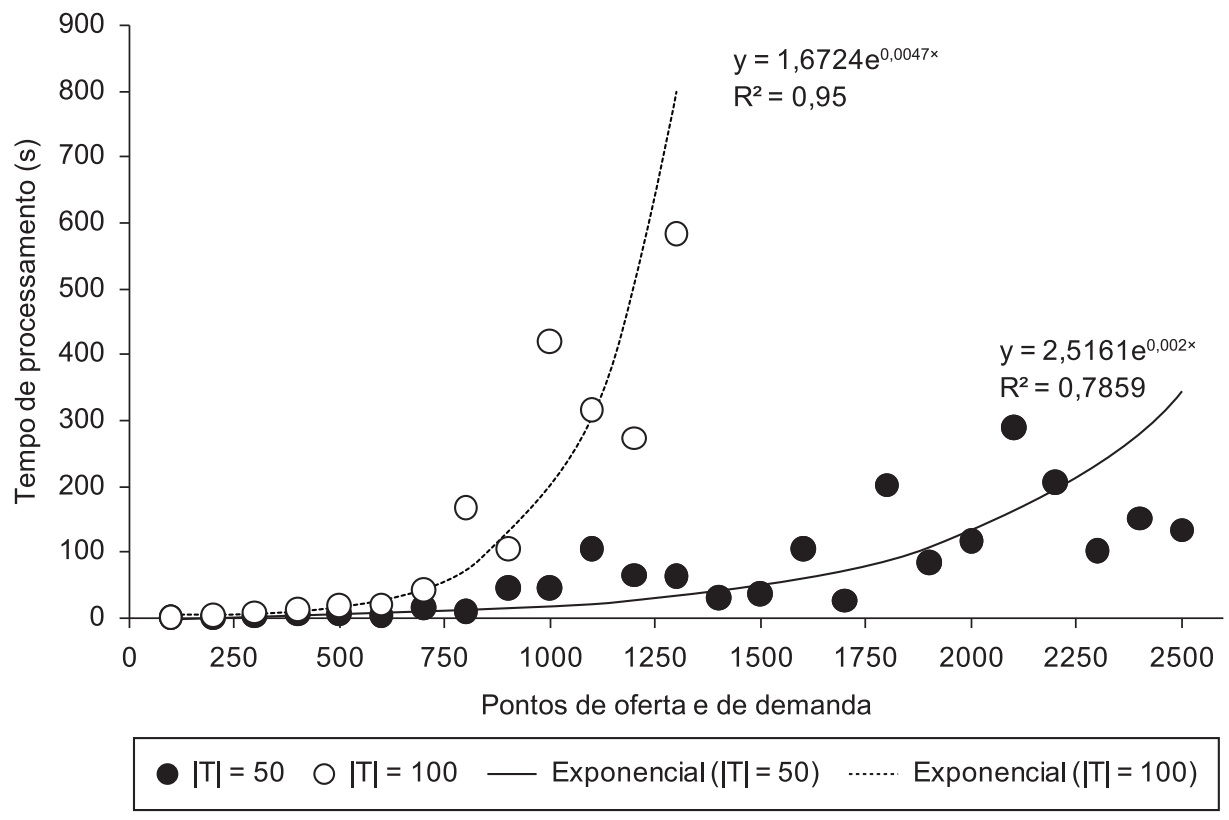

Figura 12. Tempos no AMPL/CPLEX com o aumento dos pontos de oferta e demanda. 
observam também grandes diferenças na escala nos tempos apurados para cada conjunto de testes.

Para a avaliação do comportamento do modelo com o crescimento do número de variáveis não negativas, foram realizados dois conjuntos de testes, $\operatorname{com}|T|=50$ e 100, fazendo-se $|O|=|D|=100,200, \ldots, 2.500$. Os resultados obtidos permitem afirmar que, mesmo quando o número de variáveis binárias permanece fixo, os tempos de processamento também aumentam exponencialmente. Os testes com $|T|=50$ foram concluídos, durando até 2.712,654 segundos ou 0,75 horas, mas para $|T|=100$, os testes foram interrompidos com $|O|=|D|=1.600$. Os resultados apurados são apresentados na Tabela 6 , enquanto a Figura 12 apresenta as curvas de crescimento do tempo computacional associadas aos testes.

Os poucos testes concluídos para $|O|=|D|=1.700$ duraram entre 49.211,211 e 52.982,052 segundos, ou 14,121 horas em média, demonstrando a dificuldade de utilização do AMPL/CPLEX para resolução de instâncias desse porte. Vale ressaltar que esse resultado é esperado quando se analisa a curva de crescimento do tempo computacional da Figura 12.

\section{Considerações finais}

O modelo de fluxos e localização multiníveis de terminais intermodais proposto é um modelo integrado de localização de instalações e de fluxo de custo mínimo.Variáveis binárias de localização são usadas para tomar decisões de instalar ou não um terminal intermodal para integrar modais em uma rede de exportação de soja, e variáveis não negativas de fluxo são usadas para alocar fluxos intermodais na rede com o menor custo possível. São consideradas restrições de conservação de fluxo, além de limitações no número e na capacidade dos terminais a serem instalados. Algumas extensões do modelo foram discutidas, tais como a inclusão de custos fixos de instalação para os terminais intermodais, capacitação de ferrovias e hidrovias e a consideração de fluxos bidirecionais dentro dos terminais intermodais.

Testes realizados com dados secundários demonstram a aplicabilidade do modelo para apoiar decisões na prática. Além da determinação das melhores localizações para a instalação de terminais, é possível identificar e analisar a formação de gargalos de fluxo nos mesmos. A partir de um estudo de cenários, podem-se dimensionar capacidades adequadas para esses gargalos ou identificar as melhores rotas para desvio dos fluxos, de acordo com níveis de custo e/ ou capacidade desejados. Outros testes, realizados com instâncias geradas aleatoriamente, permitiram avaliar o comportamento do modelo quando se varia $p$, em relação ao tempo para obtenção da solução ótima, à variação da função objetivo, à variação do GAP de relaxação linear e à exploração da árvore de branch-and-cut. Nesses experimentos, também se avaliou o desempenho computacional do modelo quando se aumentam os dados $|O|$ e $|D|$ ou $|T|$, utilizando-se os softwares AMPL/CPLEX e GNU GLPK. Outras extensões interessantes estão na nossa agenda de pesquisa, como a consideração de múltiplos produtos e períodos de planejamento, a inclusão de armazéns e pontos de consumo interno, e a exportaçãode produtos industrializados, como óleos vegetais e outros derivados da soja.

\section{Agradecimentos}

Os autores agradecem aos dois revisores anônimos os úteis comentários e sugestões, e também à CAPES, ao CNPq, à FAPESP e à FINEP o apoio a esta pesquisa.

\section{Referências}

AGÊNCIA NACIONAL DE TRANSPORTES AQUAVIÁRIOS - ANTAQ. Principais portos brasileiros. 2009. Disponível em: <http://www.antaq. gov.br/Portal/principaisportos.asp >. Acesso em: 12 mar. 2009.

AGÊNCIA NACIONAL DE TRANSPORTES TERRESTRES - ANTT. Relatório anual de acompanhamento das concessões ferroviárias. Disponível em: <http://www.antt.gov.br/relatorios/ ferroviario/concessionarias2007/index.asp $>$. Acesso em: 20 fev. 2010.

AHUJA, R. K.; MAGNANTI, T. L.; ORLIN, J. B. Network flows: theory, algorithms, and application. Englewood Cliffs: Prentice-Hall, 1993.

ARENALES, M. et al. Pesquisa operacional para cursos de engenharia. Rio de Janeiro: Elsevier, 2007.

ARNOLD, P. et al. Pour une localisation optimale des centres de transbordment intermodaux entre réseaux de transport: formulation at extensions. The Canadian Geographer, v. 45, n. 3, p. 427-436, 2001.

ARNOLD, P.; PEETERS, D.; THOMAS, I. Modeling a rail/ road intermodal transportation system. Transportation Research Part E, v. 40, p. 255-270, 2004.

ASSOCIAÇÃO BRASILEIRA DAS INDÚSTRIAS DE ÓLEOS VEGETAIS - ABIOVE. Complexo Soja Estatística Mensal Ano Safra 2008/09. Disponível em: <http://www.abiove.com.br/estatistica_br_0809. html>. Acesso em: 5 mai. 2009.

BALLIS, A.; GOLIAS, J. Towards the improvement of a combined transport chain performance. European Journal of Operational Research, v. 152, p. 420-436, 2004. http://dx.doi.org/10.1016/ S0377-2217(03)00034-1

BONTEKONING, Y. M.; MACHARIS, C.; TRIP, J. J. Is a new applied transportation research field emerging? - A review of intermodal rail-truck freight transport literature. Transportation Research Part A, v. 38, p. 1-34, 2004. http://dx.doi.org/10.1016/j.tra.2003.06.001

BRANCO, J. E. H. Estimativa da demanda de carga captável pela Estrada de Ferro Norte-Sul. 2007. Dissertação (Mestrado em Economia Aplicada)-Escola Superior de Agricultura Luiz de Queiroz, Universidade de São Paulo, Piracicaba, 2007. 
BULHÕES, R.; CAIXETA FILHO, J. V. Análise da distribuição logística da soja na região Centro-Sul do Brasil através de um modelo de equilíbrio espacial. Teoria e Evidência Econômica, v. 8, n. 15, p. 11-23, 2000.

CHANG, T. Best routes selection in international intermodal networks. Computers \& Operations Research, v. 35, p. 2877-2891, 2008. http://dx.doi.org/10.1016/j. cor.2006.12.025

COELI, C. C. M. Análise da demanda por transporte ferroviário: o caso do transporte de grãos e farelo de soja na Ferronorte. 2004. Dissertação (Mestrado em Administração)-Universidade Federal do Rio de Janeiro, Rio de Janeiro, 2004.

DALTO, E. J. Ferramenta de simulação para auxiliar o produtor brasileiro de soja no desenvolvimento de estratégia logística e financeira de comercialização de uma safra do produto a granel. 2003. Tese (Doutorado em Administração)-Universidade Federal do Rio de Janeiro, Rio de Janeiro, 2003.

DASKIN, M. S. Network and discrete location: models, algorithms and applications. New York: John Wiley \& Sons, 1995.

FERNANDES, G. S.; CEZAR, M. S. A logística de transportes da cadeia abastecedora de arroz na região do SINOP: tratamento mediante os métodos quantitativos. Custos e Agronegócio online, v. 1, n. 2, p. 45-69, 2005.

FERRARI, R. C. Utilização de modelo matemático de otimização para identificação de locais para instalação de unidades armazenadoras de soja no Estado do Mato Grosso. 2006. Dissertação (Mestrado em Economia Aplicada)-Escola Superior de Agricultura Luiz de Queiroz, Universidade de São Paulo, Piracicaba, 2006.

FOURER, R.; GAY, D. M.; KERNIGHAN, B. W. AMPL: A Modeling Language for Mathematical Programming. Cole Publishing Company, 2002.

GHIANI, G.; LAPORTE, G.; MUSMANNO, R. Introduction to logistics systems planning and control. Chichester: John Wiley \& Sons Ltd, 2004.

GRUPO EXECUTIVO DE INTEGRAÇÃO DA POLÍTICA DE TRANSPORTES - GEIPOT. Corredores estratégicos de desenvolvimento - alternativas de escoamento de soja para exportação. 2001. Disponível em: <http:// www.geipot.gov.br/estudos_realizados/soja/index.htm>. Acesso em: 3 jan. 2009.

INSTITUTO BRASILEIRO DE GEOGRAFIA E ESTATÍSTICA - IBGE. Sistema IBGE de recuperação automática. 2008. Disponível em: <www.sidra.ibge. gov.br>. Acesso em: 11 jan. 2010.

JARŽEMSKIENĖ, I. The evolution of intermodal transport research and its development issues. Transport, v. 22, n. 4, p. 296-306, 2007.

JUNQUEIRA, R. A. R.; MORABITO, R. Um modelo de otimização linear para o planejamento agregado da produção e logística de sementes de milho. Produção, v. 16, n. 3, p. 510-525, 2006.
JUNQUEIRA, R. A. R.; MORABITO, R. Planejamento otimizado da produção e logística de sementes de milho: um estudo de caso. Gestão \& Produção, v. 15, n. 2, p. 367-380, 2008 .

KERBACHE, L.; SMITH, J. M. Queueing networks and topological design of supply chain systems. International Journal of Production Economics, v. 91, p. 251-272, 2004. http://dx.doi.org/10.1016/j. ijpe.2003.09.002

KONINGS, J. W. Integrated centres for the transshipment, storage, collection and distribution of goods: a survey of the possibilities for a high-quality intermodal transport concept. Transportation Policy, v. 3, n. 1-2, p. 3-11, 1996. http://dx.doi.org/10.1016/0967-070X(96)00007-8

LIMBOURG, S.; JOURQUIN, B. Optimal rail-road container terminal locations on the European network. Transportation Research Part E, v. 45, n. 4, p. 551-563, 2009. http://dx.doi.org/10.1016/j. tre.2008.12.003

MACHARIS, C.; BONTEKONING, Y. M. Opportunities for OR in intermodal freight transport research: a review. European Journal of Operational Research, v. 153, n. 2, p. 400-416, 2004

OJIMA, A. L. R. O. Transporte de soja do Estado do Mato Grosso para exportação: uma aplicação de programação linear. Revista de Economia Agrícola, v. 54, n. 1, p. 33-41, 2007.

OJIMA, A. L. R. O.; YAMAKAMI, A. Modelo de programação quadrática para análise da movimentação logística e comercialização da soja brasileira. Engenharia Agrícola Jaboticabal, v. 26, n. 2, p. 552-560, 2006.

OLIVEIRA, A. L. R. Otimização de recebimento e distribuição em unidades armazenadoras de soja. 2005. Dissertação (Mestrado em Ciências)Universidade Federal do Paraná, Curitiba, 2005a.

OLIVEIRA, A. M. K. Potencial da logística ferroviária para movimentação de açúcar para exportação no Estado de São Paulo: recomendações de localização para armazéns intermodais concentradores de carga. 2005. Dissertação (Mestrado em Economia Aplicada)-Escola Superior de Agricultura Luiz de Queiroz, Universidade de São Paulo, Piracicaba, 2005b.

RACUNICA, I.; WYNTER, L. Optimal location of intermodal freight hubs. Transportation Research Part B, v. 39, p. 453-477, 2005. http://dx.doi.org/10.1016/j. trb.2004.07.001

SISTEMA NACIONAL DE FRETES - SIFRECA. Piracicaba: USP/ESALQ, 2009. Disponível em: <sifreca. esalq.usp.br/sifreca/pt/index.php>. Acesso em: $03 \mathrm{dez}$. 2009.

XAVIER, C. E. O. Localização de tanques de armazenagem de álcool combustível no Brasil. 2008. Dissertação (Mestrado em Economia Aplicada)-Escola Superior de Agricultura Luiz de Queiroz, Universidade de São Paulo, Piracicaba, 2008. 